\title{
Impacts of wave and tidal forcing on 3D nearshore processes on natural beaches. Part I: Flow and turbulence fields
}

\author{
R. Bakhtyar ${ }^{* 1}$, A. Dastgheib ${ }^{2}$, D. Roelvink ${ }^{2,3}$ and D.A. Barry ${ }^{4}$ \\ 'Davidson Laboratory, Stevens Institute of Technology, Hoboken, NJ 07030, USA \\ ${ }^{2}$ UNESCO-IHE, PO Box 3015, 2601 DA Delft, The Netherlands \\ ${ }^{3}$ Technical University of Delft, PO Box 5048, 2600 GA, Delft, The Netherlands, and Deltares, PO Box 177, \\ $2600 \mathrm{MH}$, Delft, The Netherlands \\ ${ }^{4}$ Laboratoire de technologie écologique, Institut d'ingénierie de l'environnement, Faculté de \\ l'environnement naturel, architectural et construit (ENAC), Station 2, Ecole polytechnique fédérale de \\ Lausanne (EPFL), 1015 Lausanne, Switzerland
}

(Received July 1, 2015, Revised February 2, 2016, Accepted February 9, 2016)

\begin{abstract}
The major objective of this study was to develop further understanding of 3D nearshore hydrodynamics under a variety of wave and tidal forcing conditions. The main tool used was a comprehensive 3D numerical model - combining the flow module of Delft3D with the WAVE solver of XBeach - of nearshore hydro- and morphodynamics that can simulate flow, sediment transport, and morphological evolution. Surf-swash zone hydrodynamics were modeled using the 3D Navier-Stokes equations, combined with various turbulence models $(k-\varepsilon, k-L$, ATM and H-LES). Sediment transport and resulting foreshore profile changes were approximated using different sediment transport relations that consider both bed- and suspended-load transport of non-cohesive sediments. The numerical set-up was tested against field data, with good agreement found. Different numerical experiments under a range of bed characteristics and incident wave and tidal conditions were run to test the model's capability to reproduce 3D flow, wave propagation, sediment transport and morphodynamics in the nearshore at the field scale. The results were interpreted according to existing understanding of surf and swash zone processes. Our numerical experiments confirm that the angle between the crest line of the approaching wave and the shoreline defines the direction and strength of the longshore current, while the longshore current velocity varies across the nearshore zone. The model simulates the undertow, hydraulic cell and rip-current patterns generated by radiation stresses and longshore variability in wave heights. Numerical results show that a non-uniform seabed is crucial for generation of rip currents in the nearshore (when bed slope is uniform, rips are not generated). Increasing the wave height increases the peaks of eddy viscosity and TKE (turbulent kinetic energy), while increasing the tidal amplitude reduces these peaks. Wave and tide interaction has most striking effects on the foreshore profile with the formation of the intertidal bar. High values of eddy viscosity, TKE and wave set-up are spread offshore for coarser grain sizes. Beach profile steepness modifies the nearshore circulation pattern, significantly enhancing the vertical component of the flow. The local recirculation within the longshore current in the inshore region causes a transient offshore shift and strengthening of the longshore current. Overall, the analysis shows that, with reasonable hypotheses, it is possible to simulate the nearshore hydrodynamics subjected to oceanic forcing, consistent with existing understanding of this area. Part II of this work presents 3D nearshore morphodynamics induced by the tides and waves.
\end{abstract}

Keywords: beach types; longshore flow; process-based model; rip current; turbulence; wave characteristics

*Corresponding author, E-mail: roham.bakhtyar@stevens.edu

Copyright $\odot 2016$ Techno-Press, Ltd.

http://www.techno-press.org/?journal=ose\&subpage=7 ISSN: 2093-6702 (Print), 2093-677X (Online) 


\section{Introduction}

The nearshore zone is a complex area where waves, tides, geological structure and subsurface flow all potentially play a significant role. The complex hydrodynamics affect coastal morphodynamics, foreshore profile changes, contaminant and solute exchange (Masselink et al. 2005, Bakhtyar et al. 2009a, 2011, 2013a). The prediction and quantification of hydrodynamics and morphodynamics in coastal zones are prominent aspects of many hydraulic and environmental problems, and are prerequisites for coastal engineering design (Elfrink and Baldock 2002).

One major driver of transport and circulation of contaminants in coastal areas is sea-level oscillations (Robinson et al. 2007, 2009, Xin et al. 2010). Assessing the impact of oceanic forcing on sediment and contaminant transport is essential for investigating broader environmental questions pertinent to coastal zones. Consequently, understanding of the beach environment needs to take account of the interactions between fluid flow and sediment particles on the beach, especially the role of waves and tides on foreshore profile changes. Prediction of the evolution of the nearshore morphology relies on understanding of the main processes affecting sediment transport, i.e., the relationships between sediment transport and tidal, wave and swash motions (Larson et al. 2004, Bakhtyar et al. 2011, 2012a, b).

A complete description of the interactions between oceanic forcing and beach morphology in complex coastal zones (surf and swash zones) is still lacking (Karambas 2006), although considerable work in 2D has appeared in recent years (Bakhtyar et al. 2009c, Grasso et al. 2011). However, given the interaction of mechanisms intrinsic to nearshore processes - flow movement driven by tides and waves, and sediment transport - it is unlikely that $2 \mathrm{D}$ results can be readily extrapolated to 3D (Elfrink and Baldock 2002, Christensen 2006). The response of a nearshore zone to waves and tides has not, to our knowledge, been comprehensively examined in detail in terms of flow and sediment transport characteristics. As such, it is unclear how 3D oceanic forcing generates changes in the foreshore profile.

Waves that break and collapse obliquely to the shoreline generate a current in the nearshore area that flows parallel to the shore (Longuet-Higgins 1970). The longshore current plays a significant role in sediment transport in the nearshore area and is a crucial part of most ocean engineering projects (Kumar et al. 2003). Existing models with different sediment transport relations give an extensive range of longshore transport predictions, making it hard to choose an appropriate model for different cases (Elfrink and Baldock, 2002, Bakhtyar et al. 2009a).

Existing 2D nearshore numerical models clearly cannot describe 3D effects of wave asymmetry, beach shape and longshore variations in suspended sediment concentrations. Stretching of eddies, which is characteristic of turbulence, is not properly simulated in 2D (Christensen, 2006). Further, 2D underflow profiles appear not to follow field-measured shapes (Elfrink and Baldock 2002). Possibly, this is because the 3D flow field changes the direction of mixing processes, and therefore the undertow profiles in the nearshore zone. Obviously, 2D models consider straight beaches, and so miss longshore morphology effects (Lesser et al. 2004). Existing numerical models are not proficient of discriminating the influences of tide and wave on the nearshore hydro- and morpho-dynamics in detail (Malvarez and Cooper 2000, Xin et al. 2010). 3D numerical modeling that includes these processes is needed.

Numerous researchers have investigated the interaction of sea-level motions and beach evolution. Three methods have been used to assess the nearshore hydrodynamics or/and sediment transport driven by oceanic forcing: (i) field experiments (Austin and Masselink 2006, Miles et al. 2006); (ii) laboratory measurements (Horn and Li 2006, Horn et al. 2007); and (iii) numerical 
simulations (Li et al. 2002, Haas et al. 2003, Ozkan-Haller and Li 2003, Zhao et al. 2003, Reniers et al. 2004, Shen et al. 2004, Choi and Wu 2006, Newberger and Allen 2007a, b, Bakhtyar et al. 2009b, c, d, e, 2010a, b, 2012b, 2013b, Razmi et al. 2011, Mo et al. 2013). Delft3D, a widely used hydrodynamics model, has been widely used in recent years to model complex, large-scale coastal engineering problems. Lesser et al. (2004) used Delft3D to develop and validate a 3D morphological model for different theoretical, laboratory, and field studies, and at different spatial and temporal scales. It was used also by Dastgheib et al. (2008) to model long-term morphological changes in tidal basins, with satisfactory results. Apotsos et al. (2011) investigated wave characteristics and morphological effects on the onshore hydrodynamic response of tsunamis, and showed that commonly used analytical expressions might not be appropriate. Tran et al. (2012) simulated the morphological evolution within tidal inlets subjected to a range of oceanic conditions and found the model to be a useful tool for simulating morphodynamics at field scale. Recent studies using Delft3D have investigated a variety of coastal engineering problems (van Leeuwen et al. 2003, Elias et al. 2006, Allard et al. 2008, van der Wegen and Roelvink 2008, Hu et al. 2009, Geleynse et al. 2010, 2011, van Rijn et al. 2011). Overall, Delft3D's performance has been shown to be consistent with current understanding of coastal processes under different forcing conditions, in particular beach evolution and nearshore hydrodynamics. Thus, the applicability of the model to the study of 3D nearshore hydro- and morphodynamics is, at least, partially validated (Hsu et al. 2008).

Our main objective is to investigate, using Delft3D, combined ocean hydrodynamics, sediment transport and beach morphology in a large-scale setting. For the first time, the coupling between turbulent flow field model (Delft3D) and a wave solver (XBeach) for 3D hydro- and morphodynamic simulations in field scale is validated. The results are presented in two parts: Part I considers nearshore hydrodynamics and part II the associated morphodynamics. The major areas investigated were:

- Influence of wave characteristics, sediment grain size, beach shape, bed slope and oceanic forcing (i.e., wave and tide) on nearshore hydrodynamics;

- $\quad$ Effect of longshore flows on rip-currents and undertow;

- Spatial and temporal variations in turbulence production, transformation and dissipation using various turbulence closure models (viz., $k-\varepsilon, k-L$, AEM and H-LES);

- Evolution of streamline and velocity fields in the nearshore zone under oceanic forcing;

Distribution of nearshore horizontal/vertical, longshore/cross-shore velocities, pressure and water surface elevation.

\section{Mathematical formulation}

\subsection{Governing hydrodynamic equations}

In this study we have coupled two separate numerical modules: one to calculate the water level, flow field, sediment transport and bed level changes (FLOW) and the second one to determine the wave characteristics such as wave height, spectral period, wave direction, etc. (WAVE), For the FLOW module we have used a depth averaged $(2 \mathrm{DH})$ version of the flow module of Delft3D model. This model is extensively described by Lesser et al. (2004) and Van der Wegen and Roelvink (2008). The model uses a finite difference-scheme, which solves the momentum equation including the wave generated forces $\left(F_{x}\right.$ and $\left.F_{y}\right)$ and continuity equations on a curvilinear grid with 
a robust drying and flooding scheme. The velocity field obtained by solving the equation of continuity and the momentum equations is used to calculate the sediment transport field. Every time step, as a consequence of the divergence of the sediment transport field, the bed level is updated (Delft3D-FLOW: User manual, 2009)

The wave solver of XBeach* was used for generating waves. This solver solves the wave action balance equation (Roelvink et al. 2009). The XBeach solver considers a mean frequency in the directional space, and the spectral evolution is described by: local rate of change of action density in time, propagation of action in space with celerity of $C_{x}$ and $C_{y}$, depth and current-induced refraction and spatial dissipation of wave energy due to breaking. This solver also includes the roller energy equation by including the dissipation of wave energy from the action balance as the source term. Therefore, the wave forces are determined by the wave induced and roller induced radiation stress tensors as described by Roelvink et al. (2009).

\section{Flow and wave boundary conditions}

Kinematic boundary conditions were applied at the free surface, while at the bottom a quadratic bed stress (that includes effects of wave-current interactions) formulation was used. At the landward boundary, normal velocities were set to zero. To reduce reflections at the open boundaries, a so-called weakly reflecting boundary condition was applied (water level and the normal velocity component were prescribed). Oceanic forcing was generated by specifying the surface elevation, velocity, wave height, wave period, and wave angle. The driving forces in the simulations were the incident waves that entered obliquely or perpendicular to the shore, and the tide, which propagated from south to north (Fig. 2).

The seaward boundary was determined by a time series of water levels, while lateral boundary conditions were imposed as the longshore water level gradient (i.e., Neumann boundary condition), which corresponds to a progressive wave (Roelvink and Walstra 2004)

$$
\frac{\partial \zeta}{\partial s}=\sum_{j=1}^{N} k_{j} \hat{\zeta}_{j} \sin \left(\omega_{j} t-\varphi_{j}\right),
$$

where $s$ is the longshore distance, $\zeta$ is the longshore water level, $t$ is the time, $\hat{\zeta}_{j}$ is the amplitude of $j^{\text {th }}$ tidal component, $\omega_{j}$ is the tidal component frequency, $N$ is the total number of tidal components, $k_{j}$ is the longshore wave number, and $\varphi_{j}$ is the phase difference relative to a fixed point in time and space. These values were given by Roelvink and Walstra (2004).

\subsection{Non-cohesive sediment transport}

Bed load transport was computed using a technique developed by van Rijn (2001). The magnitude and direction of the bed load at the cell centers was calculated, followed by transport rates at the cell interfaces. The sediment transport equations were solved by finite-volume methods. Transport of suspended sediment was evaluated using the advection-diffusion equation (van Rijn

\footnotetext{
* http://oss.deltares.nl/web/xbeach/ . A model developed by the US Army Corps of Engineers, UNESCO-IHE, Deltares, Delft University of Technology and the University of Miami. Last access: 02 Feb 2016.
} 
2011) as follows

$$
\frac{\partial c}{\partial t}+\nabla \cdot\left(\vec{U}^{\prime} c\right)=\nabla \cdot\left(\varepsilon_{d} \nabla c\right)
$$

where $\overrightarrow{\mathrm{U}}^{\prime} \equiv\left(U, V, w-w_{s}\right)$ is the velocity vector, $c$ is the sediment concentration, $\varepsilon_{d}$ is the sediment eddy diffusivity, and $w_{s}$ is the settling velocity of sediment.

\section{Boundary conditions of sediment transport model}

At the water surface, zero vertical diffusive flux of sediment was applied. At the bottom in every time step, bed level change as the consequence of the divergence of the sediment transport field, is calculated. At the lateral boundaries, the local equilibrium sediment concentration profile, determined based on the flow velocity at the boundary, was used to exchange sediment between model domain and outside world.

\subsection{Numerical model and procedure}

The three processes considered, namely (i) wave (wave-driven longshore and cross-shore motions), (ii) tide motions and (iii) sediment transport and morphology, were coupled using a sequential approach.

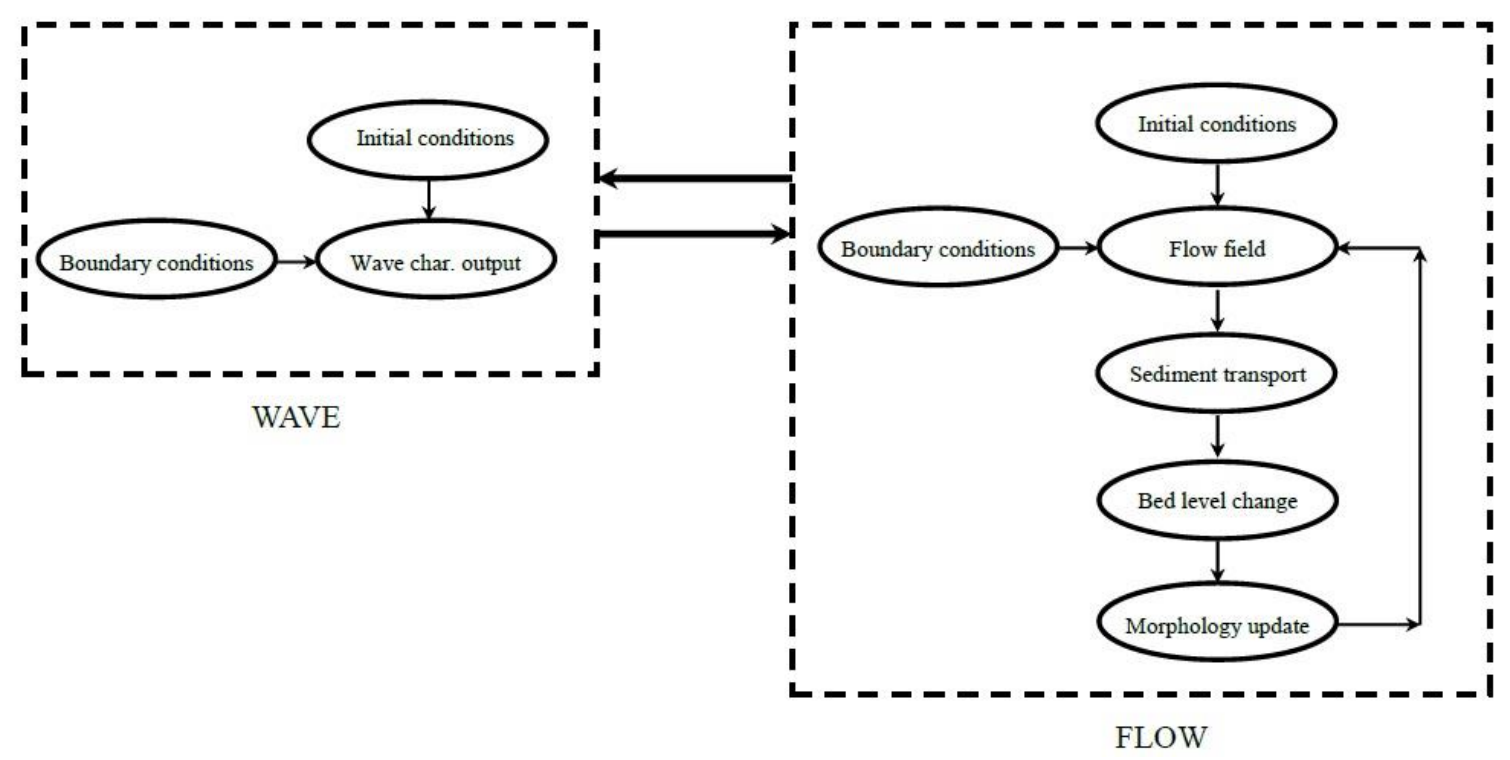

Fig. 1 Diagram of the numerical model structure, after Dastgheib (2012) 


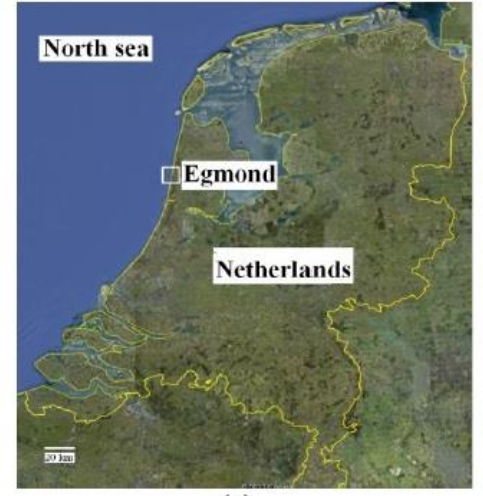

(a)
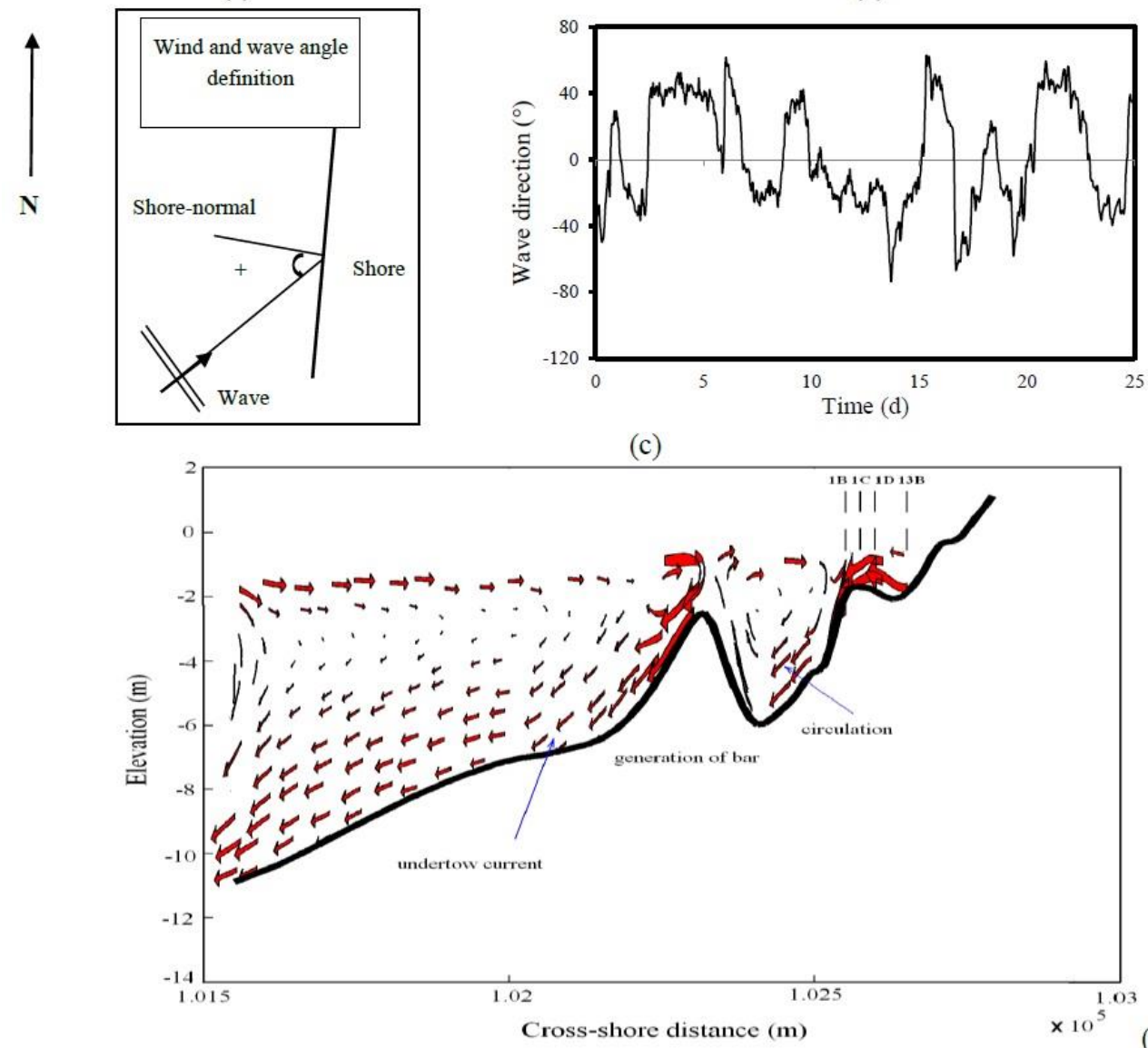

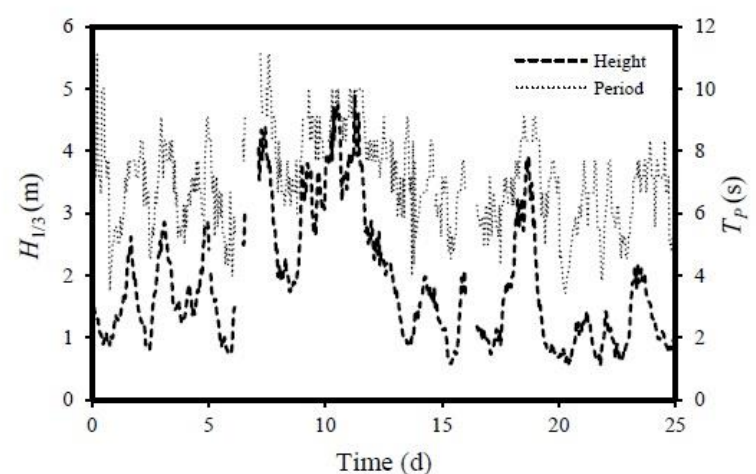

(b)

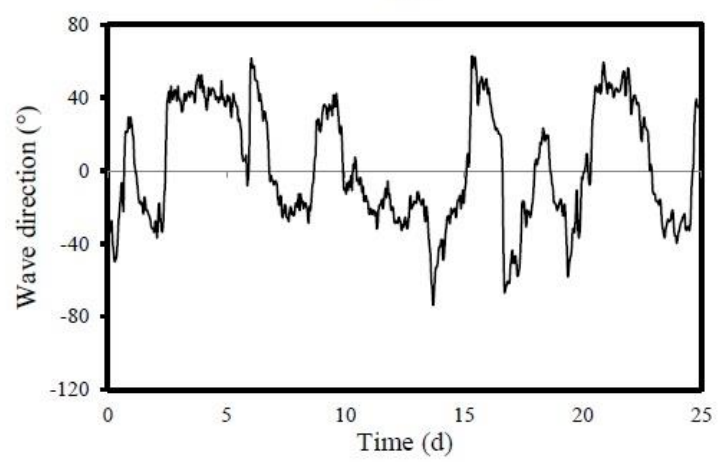

(c)

Fig. 2 (a) Plan view of survey area (Egmond aan Zee, (C) Google 2013), (b) time series of offshore wave height and wave periods (5-km offshore) used for model validation, (c) wave direction (relative to shore normal, positive counter clockwise). Data are adapted from Elias (1999) and Elias et al. (2000) and (d) Simulated cross-shore velocity distribution and location of measurement stations during October-November 1998: Stations 1B, 1C, 1D and 13B were located along the main cross-shore transect 
First, XBeach (WAVE module) was run using the initial conditions of bathymetry, water depth, and forcing boundary conditions. Then, the resulting wave characteristics were communicated to Delft3D (FLOW module). The FLOW module includes wave characteristics mainly in the form of wave-generated forces in the flow computation, which were run for a given number of time steps. After the FLOW computation had finished these time steps, the updated bathymetry, water levels, and flow field were fed back to XBeach. The updated bathymetry was used in the subsequent wave computation.

The wave calculations are done in XBeach and the radiation stresses are communicated to Delft3D flow module and used in calculating the water level, bathymetry data and flow field is communicated back from Delft3D to XBeach and this exchange of data happens every $10 \mathrm{~min}$.

Table 1 Characteristics of the oceanic forcing and beach conditions in the numerical experiments. Bold face indicates the base case and the parameter that is varied in each given subset of cases

\begin{tabular}{|c|c|c|c|c|c|c|c|c|}
\hline Case & $H_{s}(\mathrm{~m})$ & $\begin{array}{c}\text { Tidal } \\
\text { range }(\mathrm{m})\end{array}$ & $D(\mu \mathrm{m})$ & $T(\mathrm{~s})$ & $\begin{array}{l}\text { Oceanic } \\
\text { condition }\end{array}$ & $\beta$ & $\begin{array}{l}\text { Turbulence } \\
\text { closure model }\end{array}$ & $\alpha$ \\
\hline 1-base case & 2 & 2 & 200 & 7 & wave + tide & $1: 100$ & $k-\varepsilon$ & 260 \\
\hline 2 & 2 & 2 & 200 & 7 & wave + tide & $1: 100$ & H-LES & 260 \\
\hline 3 & 2 & 2 & 200 & 7 & wave + tide & $1: 100$ & $k-L$ & 260 \\
\hline 4 & 2 & 2 & 200 & 7 & wave + tide & $1: 100$ & ATM & 260 \\
\hline 5 & 2 & - & 200 & 7 & wave & $1: 100$ & $k-\varepsilon$ & 260 \\
\hline 6 & - & 2 & 200 & - & tide & $1: 100$ & $k-\varepsilon$ & - \\
\hline 7 & 0.5 & 2 & 200 & 7 & wave + tide & $1: 100$ & $k-\varepsilon$ & 260 \\
\hline 8 & 1 & 2 & 200 & 7 & wave + tide & $1: 100$ & $k-\varepsilon$ & 260 \\
\hline 9 & 1.5 & 2 & 200 & 7 & wave + tide & $1: 100$ & $k-\varepsilon$ & 260 \\
\hline 10 & 2 & 2 & 200 & 7 & wave + tide & $1: 100$ & $k-\varepsilon$ & 240 \\
\hline 11 & 2 & 2 & 200 & 7 & wave + tide & $1: 100$ & $k-\varepsilon$ & 280 \\
\hline 12 & 2 & 2 & 200 & 7 & wave + tide & $1: 100$ & $k-\varepsilon$ & 300 \\
\hline 13 & 2 & 0.5 & 200 & 7 & wave + tide & $1: 100$ & $k-\varepsilon$ & 260 \\
\hline 14 & 2 & 1 & 200 & 7 & wave + tide & $1: 100$ & $k-\varepsilon$ & 260 \\
\hline 15 & 2 & 3 & 200 & 7 & wave + tide & $1: 100$ & $k-\varepsilon$ & 260 \\
\hline 16 & 2 & 2 & 200 & 7 & wave + tide & $1: 50$ & $k-\varepsilon$ & 260 \\
\hline 17 & 2 & 2 & 200 & 7 & wave + tide & $1: 75$ & $k-\varepsilon$ & 260 \\
\hline 18 & 2 & 2 & 500 & 7 & wave + tide & $1: 100$ & $k-\varepsilon$ & 260 \\
\hline 19 & 2 & 2 & 800 & 7 & wave + tide & $1: 100$ & $k-\varepsilon$ & 260 \\
\hline 20 & 2 & 2 & 1000 & 7 & wave + tide & $1: 100$ & $k-\varepsilon$ & 260 \\
\hline
\end{tabular}


The boundary condition of each model is defined separately: XBeach is forced by monochromic waves with different $H_{s}$ and the water level boundary is imposed on the Delft3D flow model but via the abovementioned communication. The effect of water level is considered in the wave simulation. In this study the wave current interaction is not included in the simulations. Tide is forced to the model via a harmonic simple boundary condition at the sea boundary. Tide propagates from south to north; the period of the tide is $12 \mathrm{~h}$ and for each case, the tidal amplitude is different (Table 1). The so-called "oceanic forcing" in this model is only tidal force and wave, wave is constant over the duration of the simulation and simulated in stationary mode. Tide has the period of $12 \mathrm{~h}$. The simulations were subject to a spin-up of $1 \mathrm{~h}$ to remove initial condition effects. The vertical grid is a sigma grid and therefore the resolution of the grid is different in various locations and described in the model as the percentage of the depth. The grids are finer close to the sea bed and coarser close to the water level. The overall modeling approach and coupling WAVE and FLOW are shown in Fig. 1. More explanations of this feedback and stability procedure were given by Dastgheib (2012), Lesser et al. (2004) and Delft3D-FLOW: User manual (2009).

\section{Results and discussion}

First, the model was validated to confirm that results adequately simulated nearshore processes. Then, it was applied for various scenarios of oceanic forcing and different beach characteristics to investigate the response of the nearshore system under a range of realistic conditions.

\subsection{Model validation}

In this section, the results of the model are compared with field measurements at a site near Egmond aan zee (central part of the Dutch North Sea coast), which were reported by Ruessink (1999) and analyzed by Ruessink et al. (2000). The measurement campaign was carried out as part of the EU- COAST3D (Coastal study of 3D sand transport processes and morphodynamics) project (Soulsby 2001). The bathymetry of the site has significant longshore irregularities (Ruessink et al. 2000). The case represents a typical Dutch coastline with a quasi-uniform, straight, natural, sandy beach, as can be found on much of the coastlines of northeastern France, Belgium, Netherlands, Germany and Denmark (Elias 1999, Roelvink and Reniers 2012). At the time of the field experiment, the beach slope was between 1:30 and 1:50. The cross-shore profile had a double bar. The yearly-average wave height was 1 to $1.2 \mathrm{~m}$, while the offshore significant wave height can reach $5 \mathrm{~m}$ in storms. The range of tides changed between $1.4 \mathrm{~m}$ and $2 \mathrm{~m}$ for neap and spring, respectively. The effects of the wind on set-up made use of the measured wind field at Egmond. The maximum wind speed was about $20 \mathrm{~ms}^{-1}$ from the west (normal to shore). The two longshore sandbars were interrupted by rip channels. Observations were carried out in an area of about $500 \mathrm{~m}$ $\times 500 \mathrm{~m}$ in shallow water. Data were collected from October to November 1998, which is of interest for model validation since rapid changes in oceanic conditions occurred then. Both swell and waves were present and the tidal range was $2 \mathrm{~m}$ (spring tide). Fig. 2 shows a plan view of study area, time series of wave height and direction as well as the beach profile and velocity distribution along the main transect. Data from the four stations shown in Fig. 2(d), i.e., 1B, 1C, $1 \mathrm{D}$ and 13B, were used. These stations were selected because they were along one cross-section, and in all of them the same measurement devices were used, so the accuracy of the measurements was likely the same. The stations were located on or slightly onshore of the crest of the inshore bar. 
A detailed description of field data was given by Ruessink (1999).

The size of the simulated domain was $1.3 \mathrm{~km}$ and $2.5 \mathrm{~km}$ in the cross-shore and longshore directions, respectively, with water depths up to $13 \mathrm{~m}$. The van Rijn sediment formula (van Rijn 1993) and Chezy roughness formula with a Chezy value of $65 \mathrm{~m}^{1 / 2} \mathrm{~s}^{-1}$ were used. The eddy viscosity and horizontal diffusivity were 1 and $0.5 \mathrm{~m}^{2} \mathrm{~s}^{-1}$, respectively. The bed was assumed to be impermeable. The solid density was $2.65 \times 10^{3} \mathrm{~kg} \mathrm{~m}^{-3}$, while the seawater density was $1.025 \times 10^{3}$ $\mathrm{kg} \mathrm{m}^{-3}$. Generally, the grid size was non-uniform, being larger in the offshore region than in the nearshore. In the longshore direction, a finer grid was chosen in the middle of the study area, around the field measurement stations, leaving a coarser resolution in the outer regions on either side. Based on the model convergence rate, the numerical cell size was chosen to ensure that the dependence of the results on grid size is negligible. The size selected varied between $10 \mathrm{~m}$ and 75 $\mathrm{m}$ per cell, which allowed capturing of wave motion and resulting longshore currents. The resolution was such that the four field measurement stations were located in different numerical cells. The initial time step of $3 \mathrm{~s}$ was reduced during the simulations based on convergence and stability restrictions.

Figs. 3 and 4 show comparisons of model predictions and field data for water depth, velocity (longshore and cross-shore) and wave height over almost $10 \mathrm{~d}$. Tidal oscillations are given as input at the domain boundary. Their predicted propagation to the measurement stations $1 \mathrm{~B}, 1 \mathrm{C}$ and $1 \mathrm{D}$ is satisfactory (Fig. 3(a)). The phase and amplitude of the tidal fluctuations are well reproduced. There is an initial offset of $0.5 \mathrm{~m}$ between the predicted and the measured water depths, which was progressively removed over the first $4 \mathrm{~d}$. From then on, there are only a few instances where an offset up to $0.25 \mathrm{~m}$ and lasting no longer than a $1 \mathrm{~d}$ is observed. The $0.5 \mathrm{~m}$ difference which is seen in the real case is due to the wind setup. In this case the model is forced with actual water level measured at the boundary so no tidal component is included in the forcing of the model.
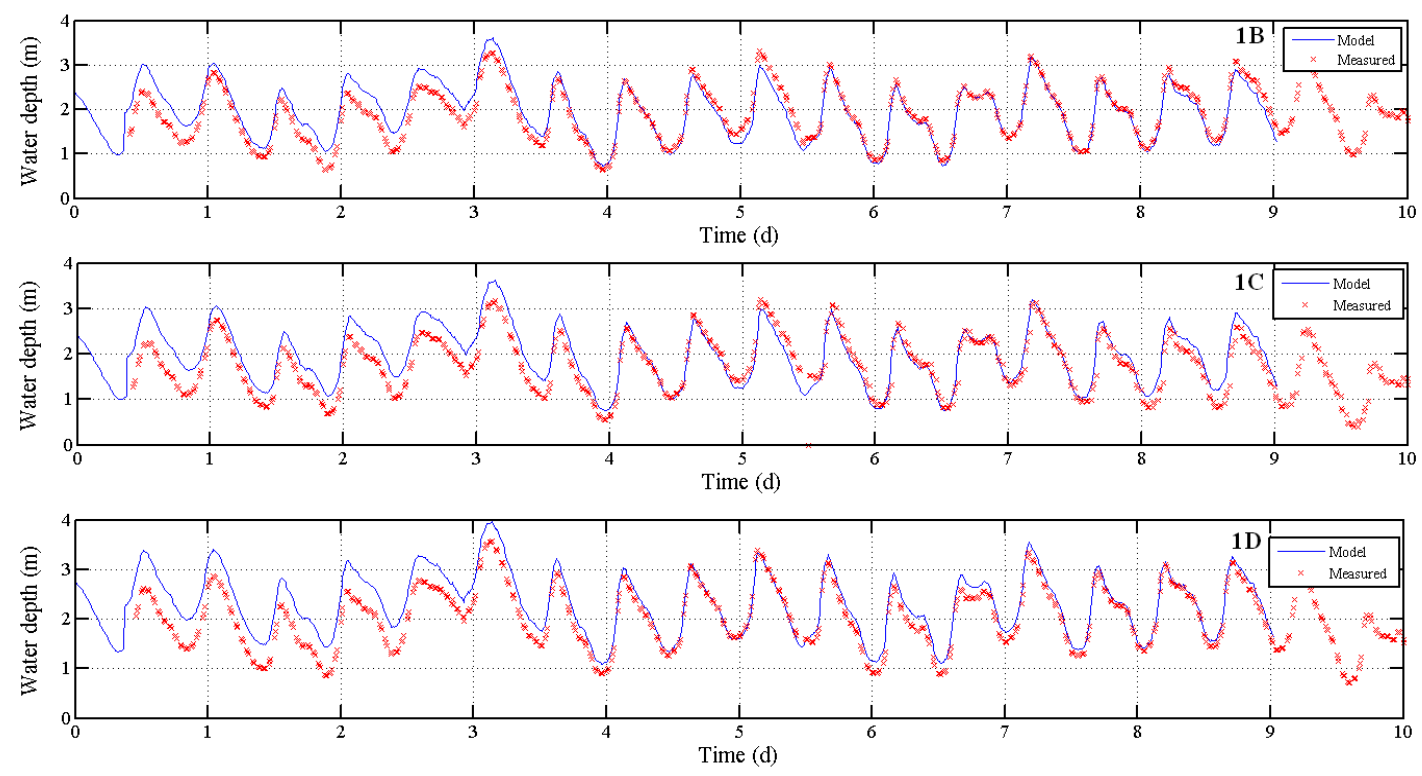

(a)

Continued- 

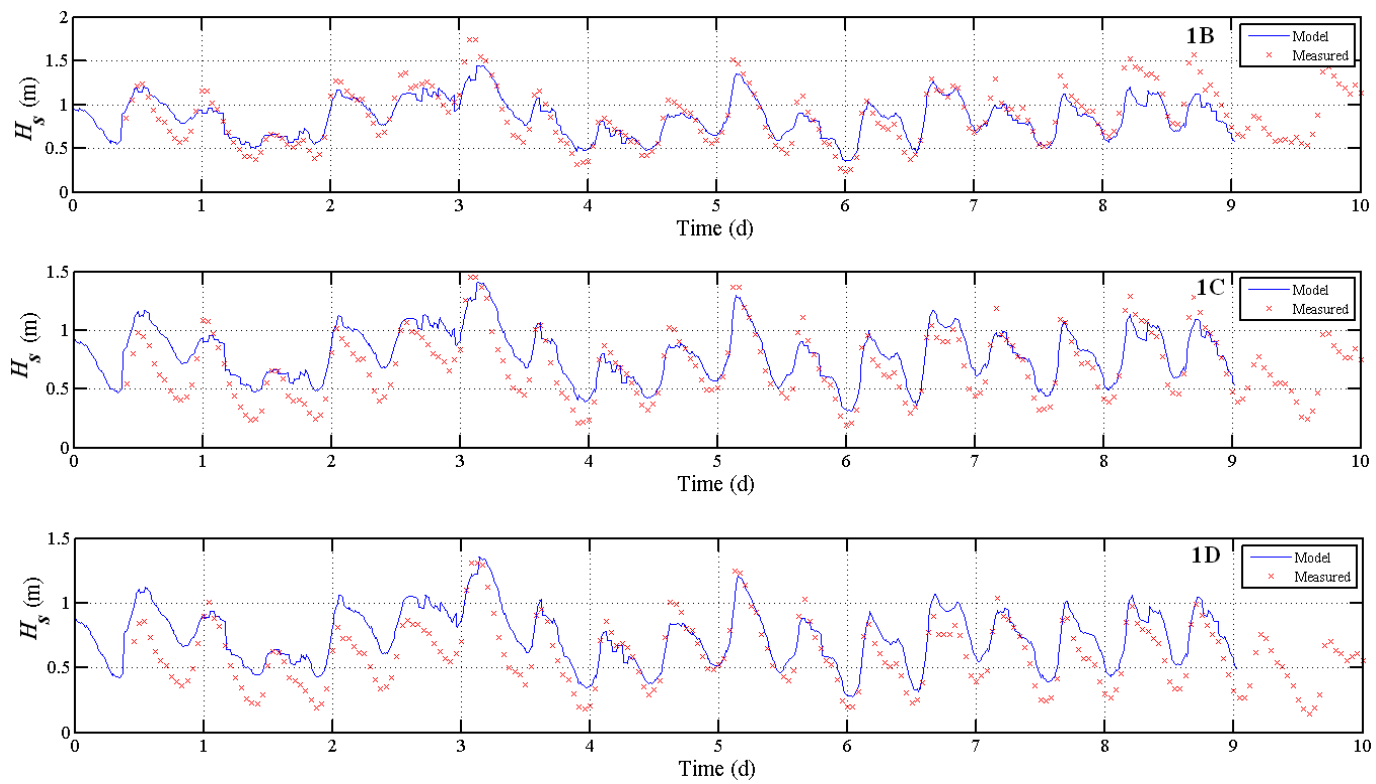

(b)

Fig. 3 (a)Water depth and (b) significant wave height comparison between model and data at different stations (listed in figures)

In addition, for a statistical comparison of the numerical results and experimental measurements, the bias (mean error), the root mean square error (RMSE), scatter index (SI) and the determination coefficient $\left(R^{2}\right)$ were calculated. For the station $1 \mathrm{~B}$, the values of bias, SI and RMSE are $0.044 \mathrm{~m}, 8.56 \%$ and $0.16 \mathrm{~m}$, respectively. Therefore, the water depth is slightly over-predicted. To assess the performance of the model, observed water depth is plotted against the predicted one. Panel (b) of Fig. 5 shows the results with the performance indices between predicted and observed data. Fig. 5 properly demonstrates that model performance is, in general, accurate and good, where all data points are quite near the line of agreement.

The model reproduces rather well the measured significant wave height (Fig. 3(b)). For the station 1B, the values of bias, SI, RMSE and $R^{2}$ are $-0.0063 \mathrm{~m}, 11.69 \%, 0.103 \mathrm{~m}$, and 0.80 (Fig. $5(b))$, respectively. There are discrepancies, but the order of magnitude and the overall pattern of the time series match. The trend and magnitude of the resulting $H_{s}$ is fine to show that model produces reasonable results. The main reason for the difference in the magnitude of the wave height can be attributed to effect of wind on the breaking of waves, especially when the direction of the wind is from land to the sea. During the first $4 \mathrm{~d}$ of the experiment period, the predictions are consistent with the measurements at station $1 \mathrm{~B}$ and overestimate them by $0.25 \mathrm{~m}$ at stations $1 \mathrm{C}$ and 1D. The agreement is good at all three stations during days 5 and 6 . The predictions remain good until the end of the experiment at station $1 \mathrm{C}$, while intermittent offsets are observed at the end of the period at station 1B (up to $0.5 \mathrm{~m}$ underestimation) and $1 \mathrm{D}$ (about $0.2 \mathrm{~m}$ overestimation). From day 3, fluctuations in both predicted and measured time series are in phase and their amplitudes are in close agreement at these three stations. Note that these fluctuations in the significant wave height occur at the tidal frequency, about 2 cycles per day. That is, the wave height is modulated by the high and low water. Besides a direct effect of increased wave height 
with increasing water depth at high tide, this tidal modulation could also result from a second-order, non-linear interaction between waves and tidal currents.
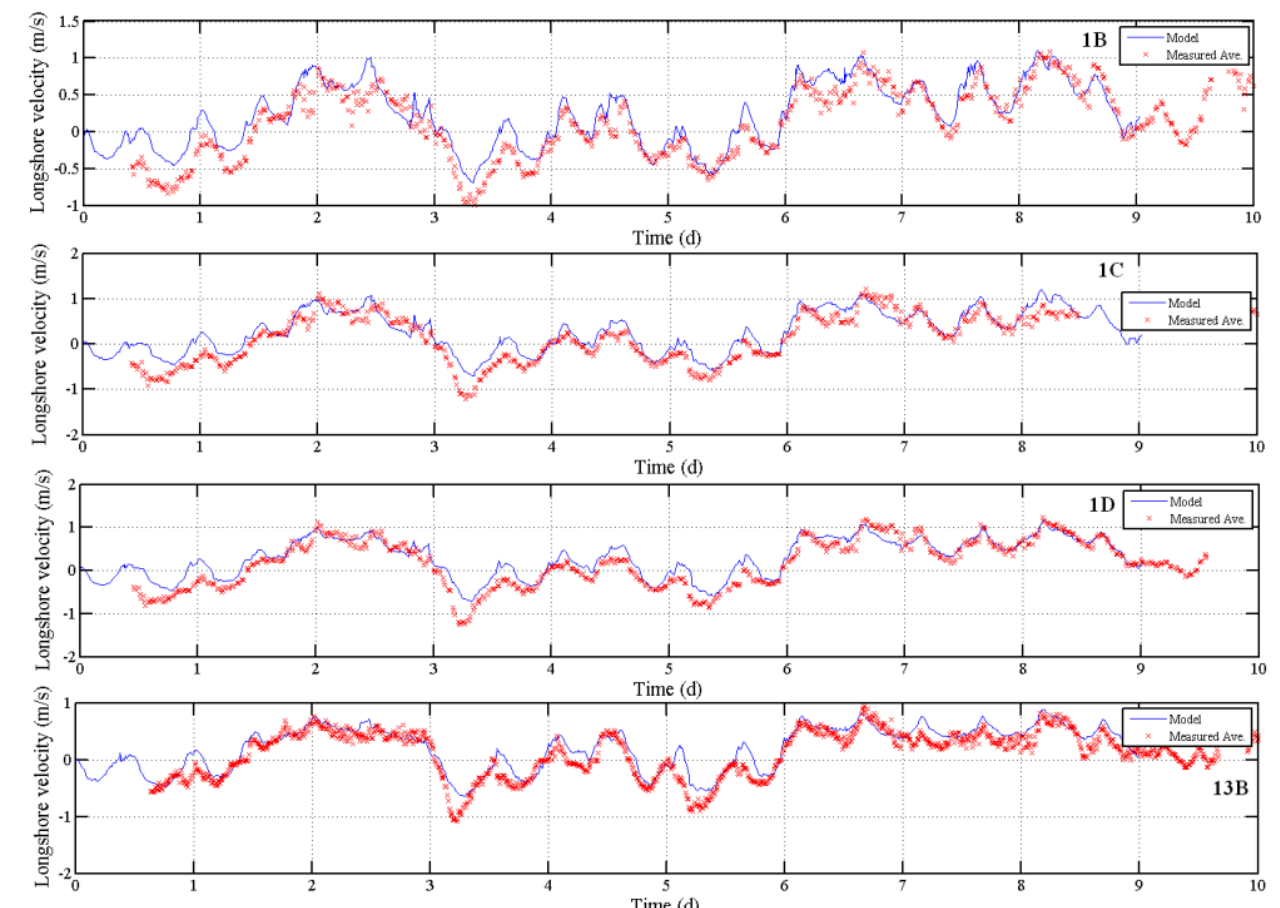

(a)
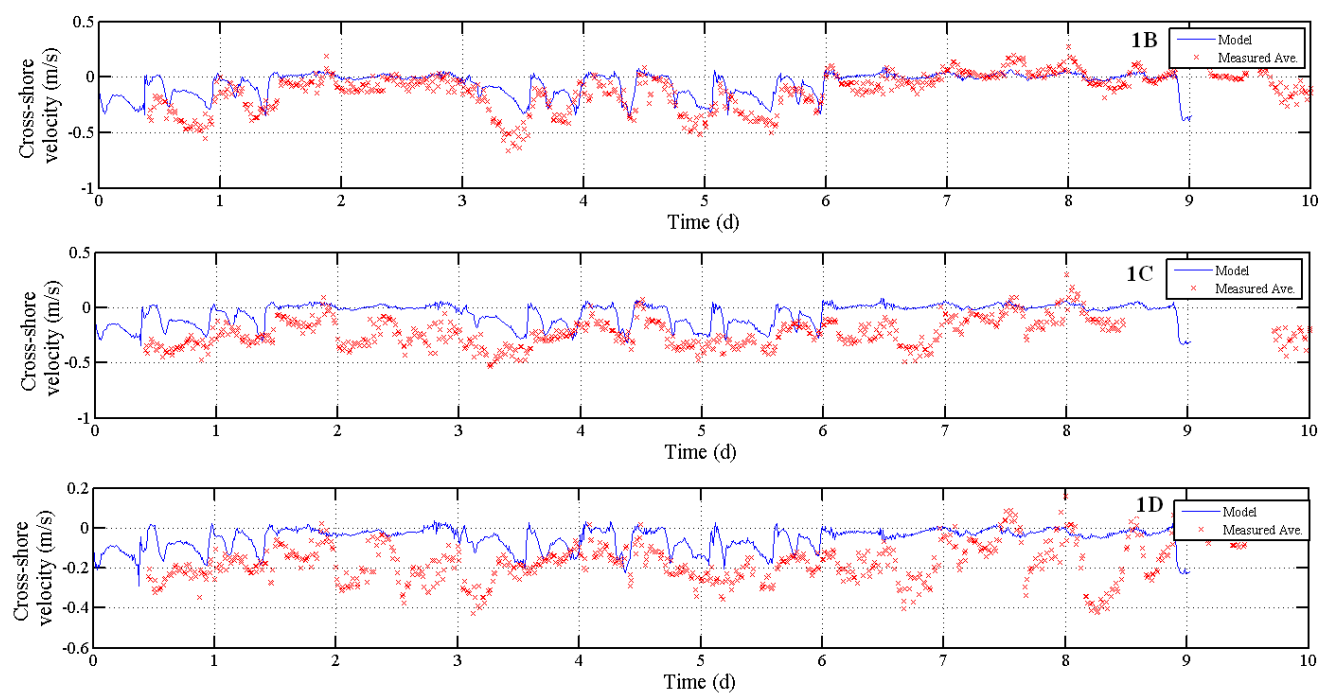

(b)

Fig. 4 (a) Longshore and (b) cross-shore comparison between model and data at different stations (listed in figures) 
Fig. 4 shows the time series of calculated and measured cross-shore and longshore velocities at differet stations. The cross-shore and longshore currents are compared at the depth of actual measurements. The agreement is indeed sensitive to the turbulence model used but we have shown the best output, the instantaneous results in time are compared with the simulation, the horizontal axis of the figures is time, so all the parameters are compared in one point (measured in the field) for the duration of the simulation. The prediction of longshore currents is good (Fig. 4(a)). The longshore current alternates between northward and southward, with a maximum of about $1 \mathrm{~ms}^{-1}$. The three measurement stations $1 \mathrm{~B}, 1 \mathrm{C}$ and $1 \mathrm{D}$ were located within $50 \mathrm{~m}$ of each other and the spatial variability in longshore velocity measured at these three stations was small. Discrepancies between measured and predicted longshore currents usually consists of errors in the current magnitude (e.g., day 4 for all four stations or day 8 for station 13B), reaching up to $0.5 \mathrm{~ms}^{-1}$. For the station $1 \mathrm{~B}$, the values of bias, SI and $R^{2}$ are $0.066 \mathrm{~ms}^{-1}, 18.15 \%$ and 0.83 (Fig. 5(d)), respectively. The temporal pattern of variation in longshore current is well predicted, except for occasional time lags (e.g., day 6 for station 13B). Agreement was particularly good during intervals at certain stations (e.g., day 3 at station 13B or days 8 and 9 at station 1D). Finally, a tide-induced modulation is also present in the longshore current, although it is less obvious than for the significant wave height (Fig. 4(a)). Such a modulation of the longshore current is quite well predicted by the model.

The model's capacity to predict cross-shore currents is not as good (Fig. 4(b)). The cross-shore current is almost exclusively oriented offshore, with maximum intensity around $0.5 \mathrm{~ms}^{-1}$, until day 7, after which brief periods of onshore current occur. The model predictions for the cross-shore current are acceptable at station 1B but their accuracy deteriorates at stations 1C and 1D. At station $1 \mathrm{~B}$, the model reproduces the measurements when the cross-shore current is low (e.g., days 3, 8 and 9) and is able to capture some events with higher flow rates (e.g., most of day 5). The values of bias, SI, and $R^{2}$ are $0.068 \mathrm{~ms}^{-1}, 12.84 \%$ and 0.54 (Fig. 5(c)), respectively. The mismatch between predictions and observations at stations $1 \mathrm{C}$ and $1 \mathrm{D}$ is noticeable during the periods between days 1.5 and 3 and between days 6 and 9. For each, the measured cross-shore velocity was close to zero at station $1 \mathrm{~B}$ and increased moving onshore to stations $1 \mathrm{C}$ and $1 \mathrm{D}$, where large amplitudes were recorded. The model does not capture this small scale spatial variability of the cross-shore velocity, as observed between the three nearby stations. This is likely due to the fact that the nearshore zone is highly complex, and wave breaking induces high curvature and consequently strong vorticity (Fig. 2(d)). The model does not give satisfactory results for the cross-shore velocity near the beach face. In fact, the time series of predicted cross-shore velocity remains practically unchanged between the three stations $1 \mathrm{~B}, 1 \mathrm{C}$ and $1 \mathrm{D}$. In addition, both measured and predicted cross-shore current velocities exhibit high-frequency fluctuations.

Modeling of certain wind effects could alter the accuracy of cross-shore velocity predictions. As mentioned above, only the wind field of Egmond is used for entire model, which likely does not correspond with the wind field for the entire North Sea. In particular, the wind field measured in the nearshore area was suggested to be less intense than the wind further off-shore (Elias 1999). Indeed, over the North Sea a variable wind field is present, therefore some inaccuracies in the representation of the wind set-up are present (Elias et al. 2000). Wind plays an important role in the flow field and circulation patterns, e.g., it creates a water level change, while wind-driven currents affect tide-driven currents. During the measurement period, the off-shore wind can cause a delay in wave breaking, an effect that is not included in the model. Overall, the model was found to be suitable for the prediction of nearshore current velocity, although the difficulty of simulating the 3D circulation of beach systems is highlighted. 


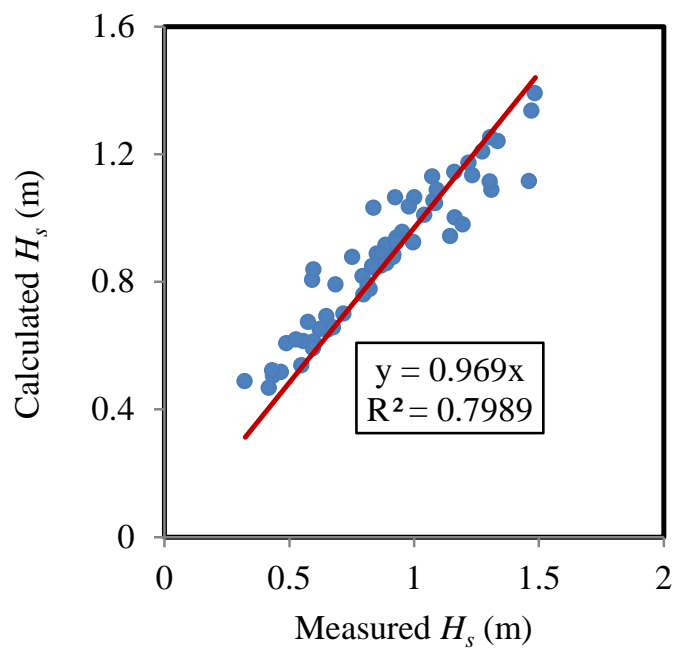

(a)

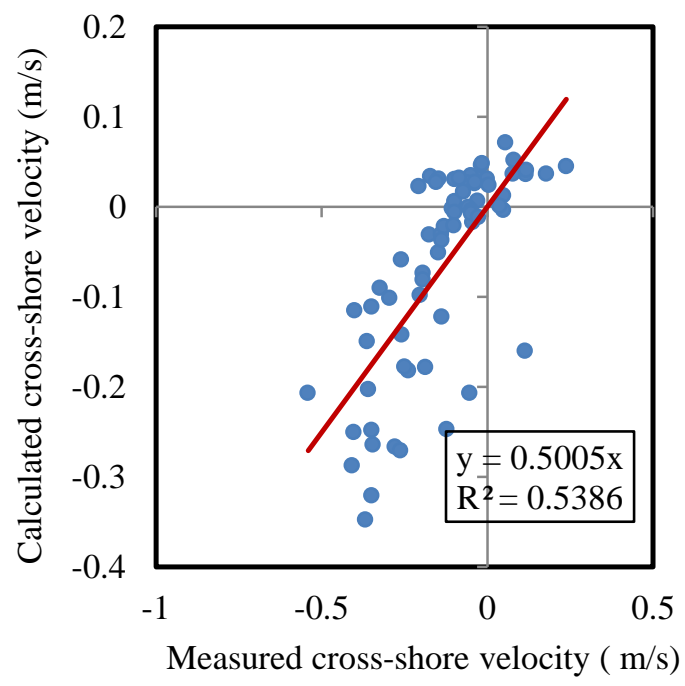

(c)

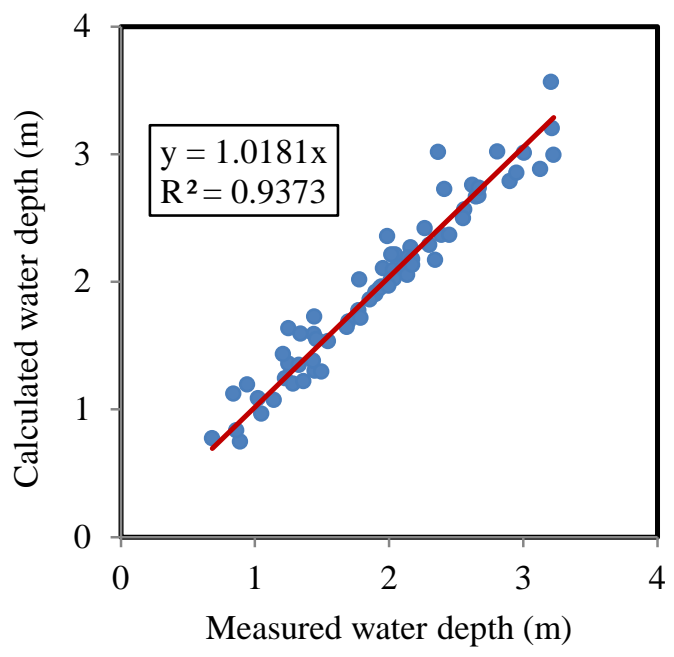

(b)

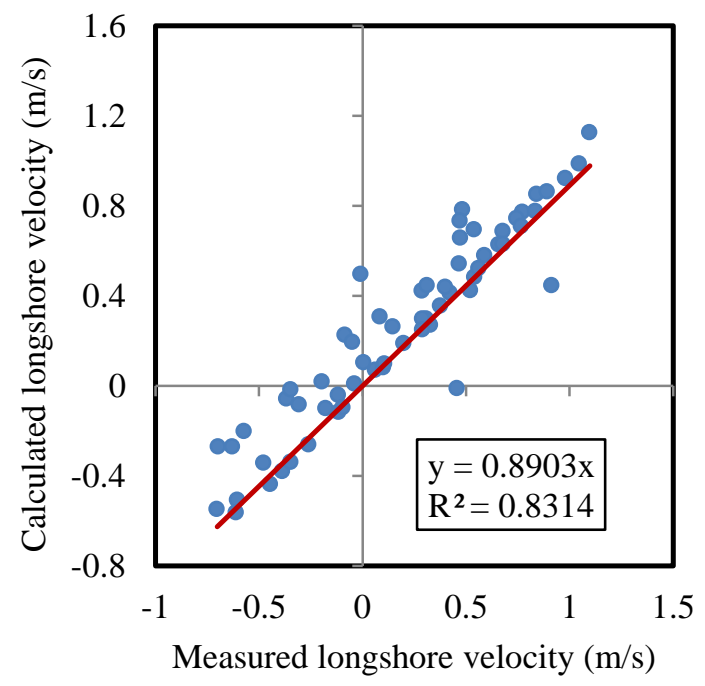

(d)

Fig. 5 Comparison between observed and predicted (a) wave height, (b) water depth, (c) cross-shore velocity and (d) longshore velocity for the station $1 \mathrm{~B}$

The distribution of simulated velocity at Egmond beach shows a rather complex flow pattern (Elias 1999, Elias et al. 2000), especially inshore of the surf zone (Fig. 6(a)). The plan view of the surface, time-averaged velocity field highlights a rip current, which occurs when incident waves propagate toward the coast at an oblique angle. At the coast, these waves have longshore variations in set-down and set-up, leading to differential wave breaking. Rip currents, which occur in areas with large longshore variability in wave height, are the result (MacMahan et al. 2006). Longshore 
wave height differences can also arise from the presence of longshore morphological variations in the nearshore profile. The mean water surface increases over nearshore bars, provoking a strong divergent flow. Results show that the model is capable of predicting strong rip currents, consistent with observations made in the Egmond area (van Duin and Wiersma 2002). Fig. 6 shows the relation between the circulation and the topography, where the low relief area in the inshore region corresponds to the longshore position where the water is funneled offshore. There is another low relief area in the inshore region further north, but of much smaller extent and that does not give rise to an offshore current but to a strong vortex (Fig. 6(a)). The local reversal of the longshore current in the inshore region causes a transient offshore shift and strengthening of the longshore current. The cross-shore excursion of the longshore current is associated with enhanced shear stress in the nearshore region. Note the strong prevalence of the southward feeder current, in the upper half of the study area, over the more discrete northward feeder current, in the lower half of the study area (Fig. 6(a)). This indicates a background southward longshore current, besides the dominant feature of the rip current.

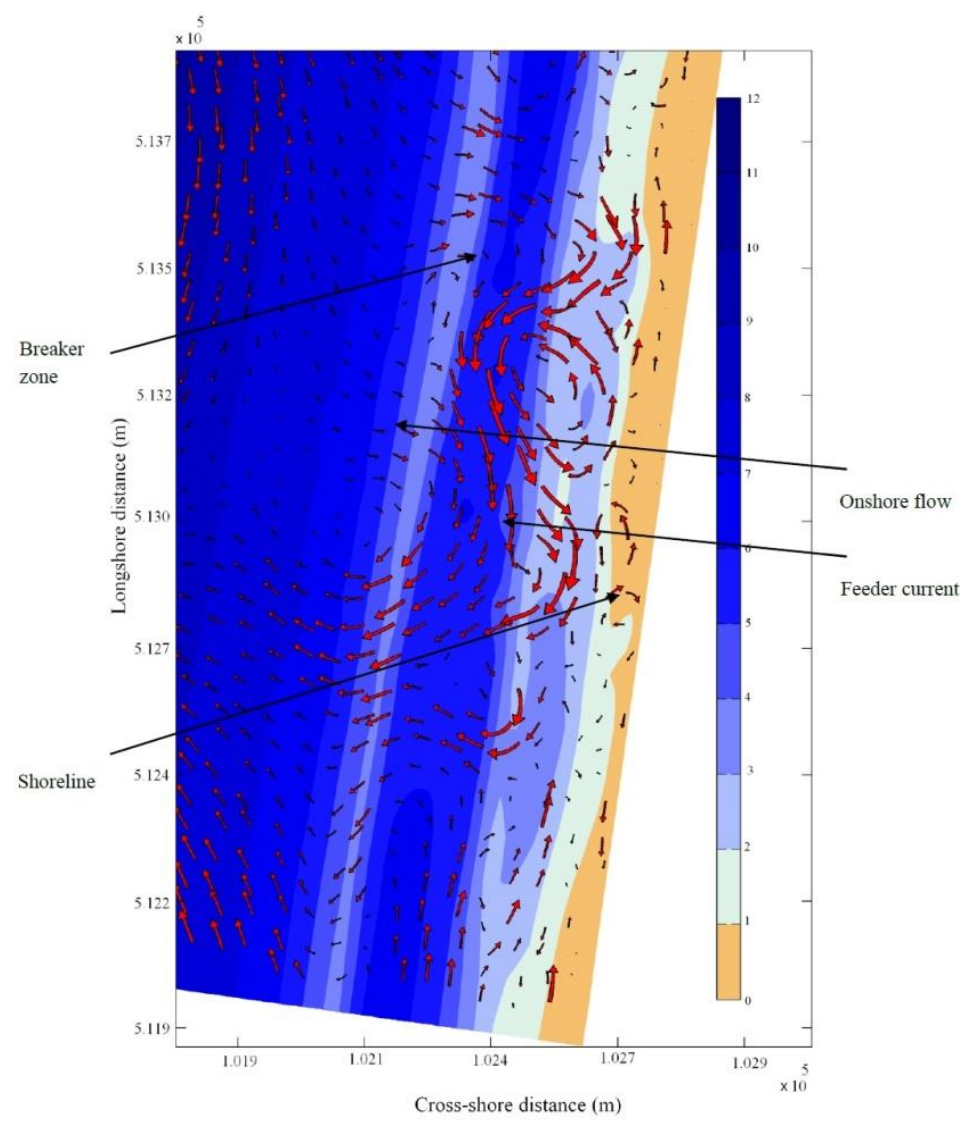

(a)

(a)

Continued- 


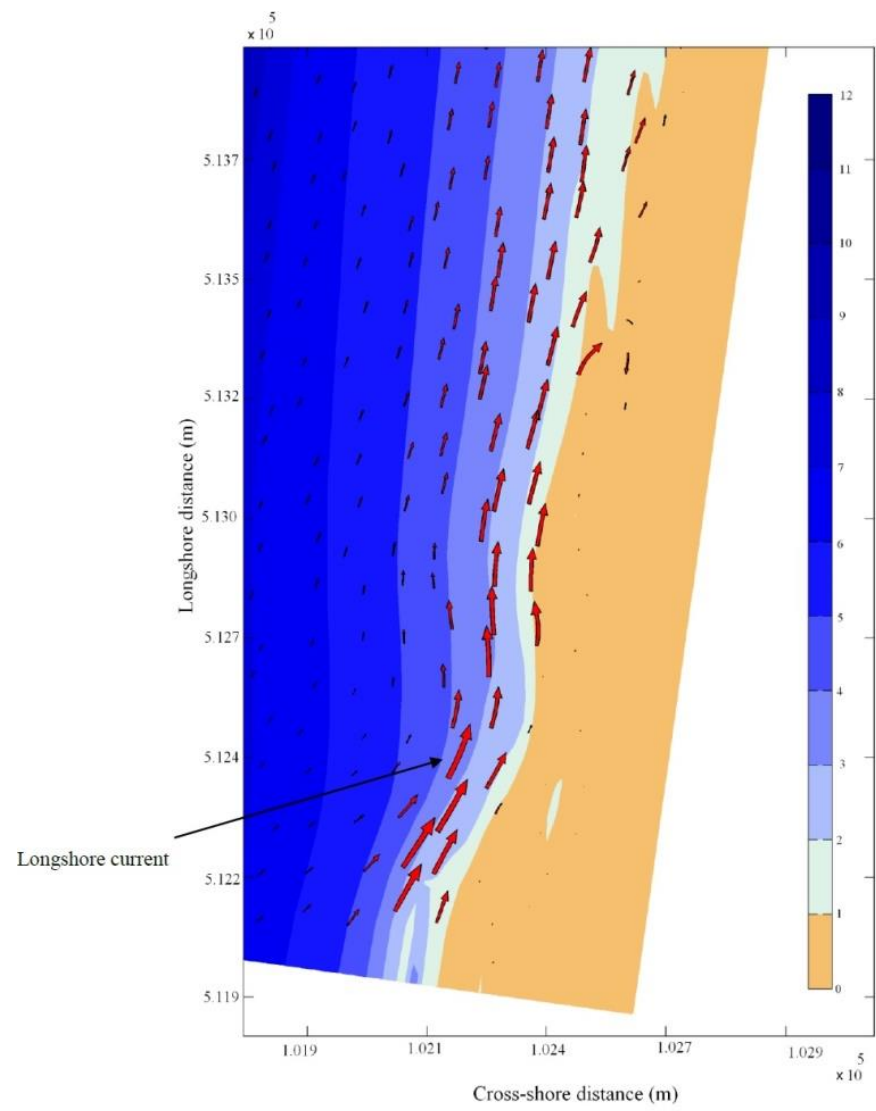

(b)

(b)

Fig. 6 Plan view of velocity distribution and rip current: (a) at Egmond beach and (b) for case 1. Horizontal and vertical axes show cross-shore and longshore distances in $\mathrm{m}$, respectively; while the color-bar shows the water depth in $\mathrm{m}$

\subsection{Numerical experiments}

The same computational grid and parameters for the validated model were used for numerical experiments, with constant initial cross-shore slope equate to alongshore uniform bathymetry. Twenty numerical experiments were performed. Relevant parameters were varied in sequence to examine their influence on the hydrodynamics of the nearshore zone. Table 1 summarizes the properties of each of the twenty cases, where $H_{s}$ is the significant wave height, $A$ is the tidal amplitude, $T$ is the wave period, $D$ is the grain size, $\beta$ is the bed slope, and $\alpha$ is the direction of wave propagation. Simulations were conducted using four different turbulence closure models: (i) $k-\varepsilon$, (ii) H-LES, (iii) $k-L$ and (iv) ATM, and three different oceanic forcing conditions: (i) combined wave and tide, (ii) tide and (iii) wave. A range of magnitudes were investigated for each forcing condition, wave and tide, as well as a series of incident swell angles. Three initial beach face slopes were considered, 1:100, 1:75 and 1:50. The median sediment diameters were 200, 500, 800, $1000 \mu \mathrm{m}$. In all cases, the model was run to simulate a one-month period. The figures show the 
final bathymetry after the one month simulations. After one month the simulations reach the state that the bed level averaged over a tidal cycle is steady. The simulations all used a zero wind speed.

In \$3.2.1, the simulated nearshore hydrodynamics for the reference case are presented (Case 1). The simulated hydrodynamics for different turbulence closure models (Cases 1-4), different oceanic forcing (Cases 1, 5, 6), various tide and wave conditions (Cases 1, 7-15), and beach characteristics (Cases 1, 16-20) are presented and discussed in $\$ 3.2 .2$ to $\$ 3.2 .5$, respectively.

\subsubsection{Predictions of nearshore hydrodynamics with DELFT3D: Reference case}

A detailed overview of the simulated hydrodynamics for case 1 is presented through several 2D views considering different variables. The plan view of the velocity distribution (including the rip current) for case 1 is shown in Fig. 6(b). A comparison between the velocity patterns on the beach with uniform slope (Fig. 6(b)) and real beach (various bathymetries, Fig. 6(a)) reveals that nearshore bathymetry facilitates the process of rip current generation. While the bed slope is uniform, rips are not generated. Previous studies showed that edge waves are a critical element in the formation of rip currents and are needed for cusp formation (Guza and Inman 1975). As in the numerical experiments, these authors assumed monochromatic waves and a long straight beach, so the numerical results are consistent with their finding. Fig. 7 shows vector and contour plots of surface velocity (plan view), cross-shore sections of the horizontal and vertical velocity components averaged in the longshore direction, and significant wave height. Fig. 8 depicts cross-shore sections of the turbulent kinetic energy (TKE) and eddy viscosity averaged in the longshore direction. The longshore position corresponding to the highest sediment flux is represented. The main feature in the coastal circulation is the northward longshore current (Figs. 7(b) and 7(d). An intertidal bar and trough system forms on the upper beach, at the cross-shore range of $102.4-102.6 \mathrm{~km}$ (Fig. 7(d)), isolating a channel of quiescent water along the beach berm from the rest of the nearshore region. Such a ridge-and-runnel morphology is common on these coastlines (e.g., Reichmuth and Anthony 2002). Two sub-tidal bars can be observed in the beach profile (in 2D sections, Figs. 7(d) and 7(e)), at cross-shore positions of 102.2 and $101.8 \mathrm{~km}$. The first, most nearshore bar corresponds to the surf break. It is much less prominent than the second bar further offshore. The second bar delineates the closure depth, of about $6 \mathrm{~m}$, consistent with typical values along the Dutch coast (e.g., van Rijn 1997). Figs. 2(d) and (7) reveal that the model generated a double bar in agreement with observations of these coastlines for both the validation and case 1 . However, locations of bars are different for case 1 and for the validation case: In case 1, the 'intertidal' bars are $1 \mathrm{~m}$ above the SWL, between $102.4 \mathrm{~km}$ and $102.6 \mathrm{~km}$ cross-shore, while the small sub-tidal bars are located 3.5 and $6 \mathrm{~m}$ below the SWL, at 101.8 and $102.2 \mathrm{~km}$ cross-shore. In the validation case, the two bars are 1 and $3 \mathrm{~m}$ below the SWL, at 102.3 and $102.6 \mathrm{~km}$ cross-shore, while there seems to be a small bar at $6 \mathrm{~m}$ below the SWL, at $101.8 \mathrm{~km}$ cross-shore, and a berm near the SWL, at $102.7 \mathrm{~km}$ cross-shore.

The shallower bar corresponds to a marked decrease of beach slope with distance to shore, as well as a sharp change in hydrodynamics. A strong gradient in horizontal velocity indicates the seaward limit of the longshore current (Fig. 7(d)). Downward velocities are spatially limited to the surf zone, between the intertidal bar and the first sub-tidal bar, and confined to the lower part of the water column (Fig. 7(e)). Downward flow coincides with large horizontal velocities (Figs. 7(d) and (e)). This feature is presumably the signature of a strong undertow accompanying the longshore current. The vertical velocity component in this localized near-bottom area with downward flow is about five times larger than the average vertical velocity in the rest of the nearshore water column. 


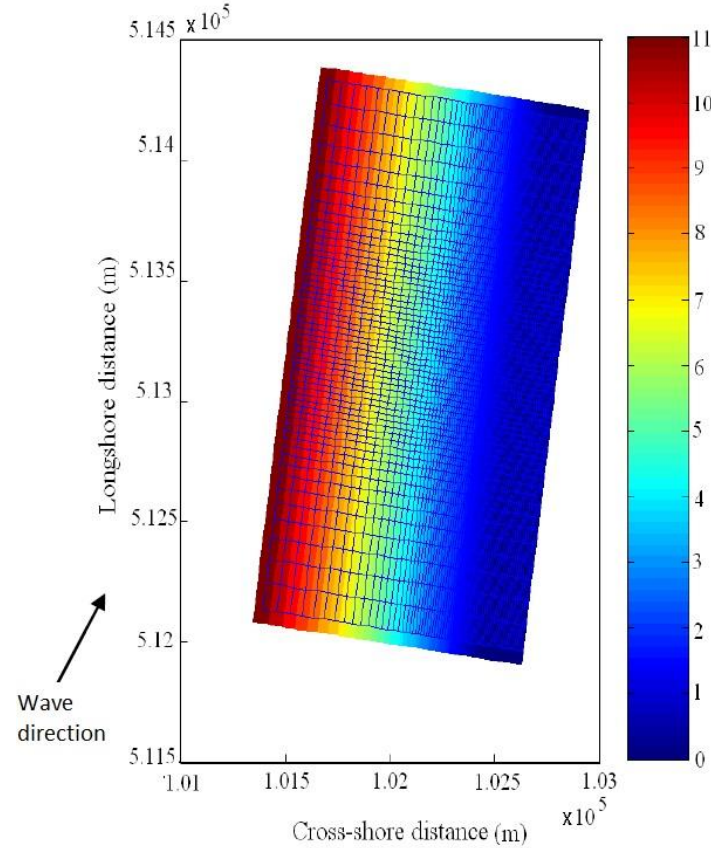

(a)

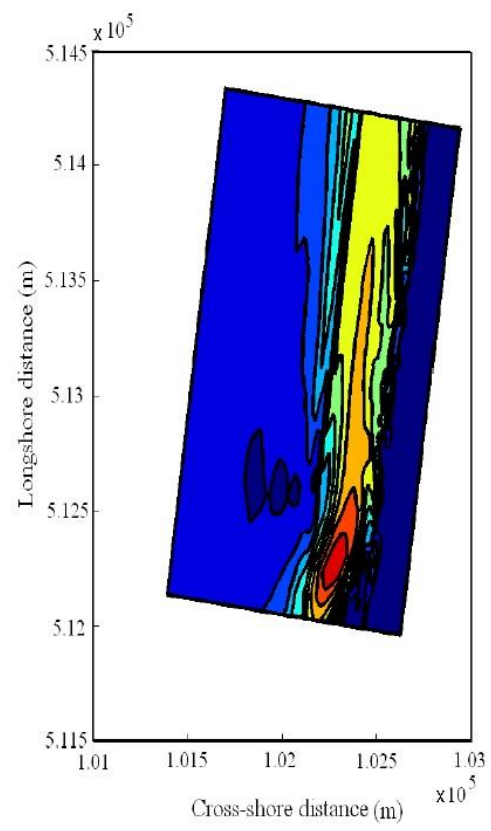

(c)

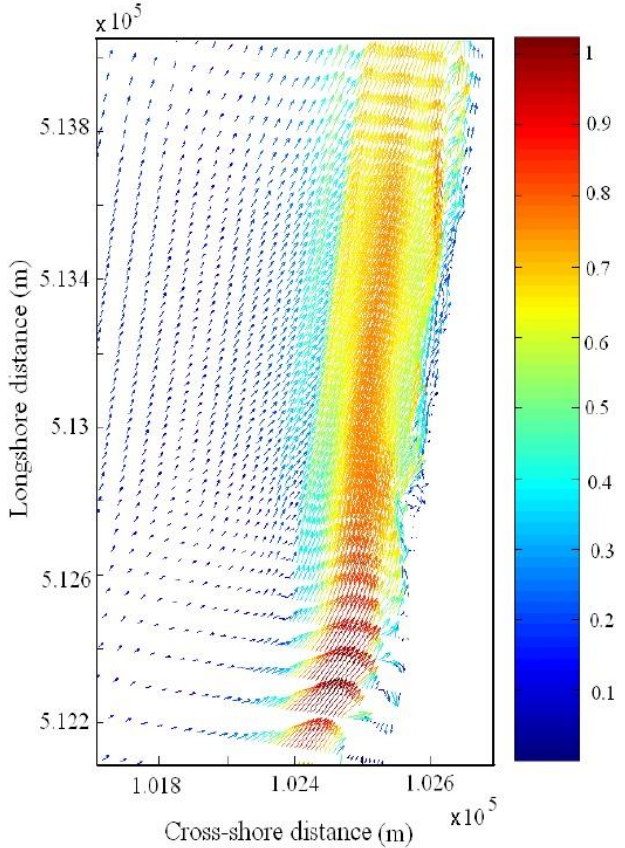

(b)

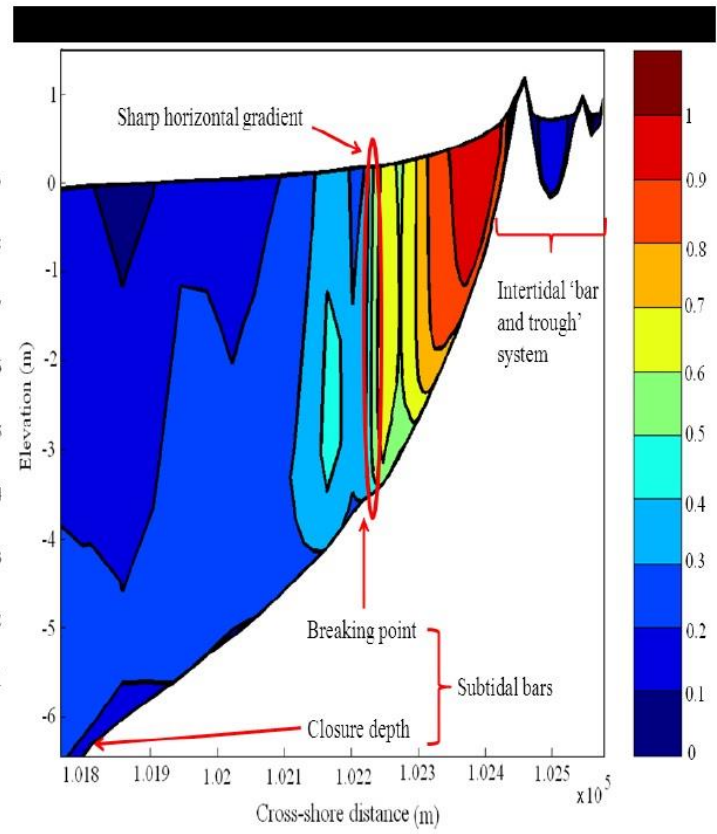

(d)

Continued 


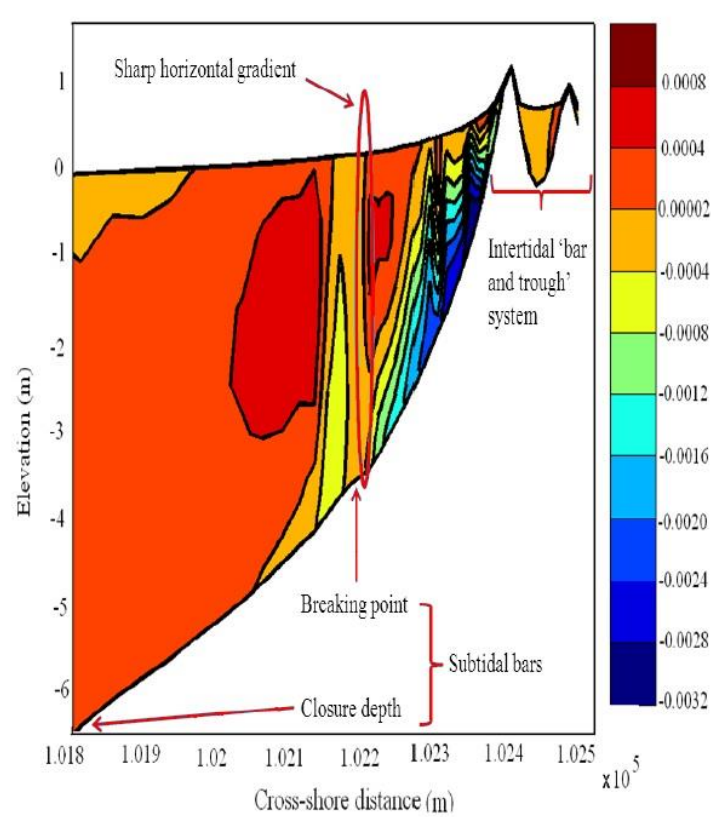

(e)

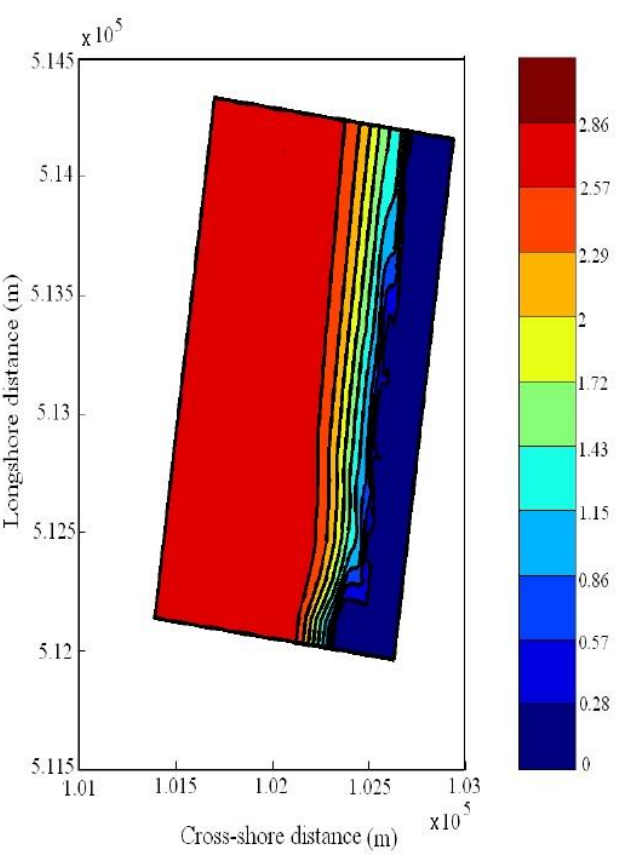

(f)

Fig. 7 (a) Bathymetry and computational mesh used in the case study, (b) velocity vectors, (c) velocity contours. Cross-shore distribution of (d) horizontal and (e) vertical velocities, and (f) significant wave height for case 1 ( $\beta=1: 100, A=2 \mathrm{~m}, \alpha=260^{\circ}, H=2 \mathrm{~m}$, combined wave and tide, $k$ - $\varepsilon$ turbulence model, $D=200 \mu \mathrm{m})$. Velocity and wave height units are in $\mathrm{ms}^{-1}$ and $\mathrm{m}$, respectively

The observed longshore variability in the current velocity (Fig. 7(c)) can be interpreted in terms of the interaction between flow and topography. The longshore flow is accelerated just down-current of the seaward bulge observed in the coastline at about $512.8 \mathrm{~km}$ north (Figs. 7(b) and 7(c)), and decelerated up-current of the bulge. The coastline bulge acts as an obstacle to the longshore current. A local increase in set-up occurs immediately up-current of the bulge, which strongly affects wave propagation and collapse. The width of the surf zone is significantly reduced in the area of increased longshore velocity and steadily increases past the bulge, as can be seen with the changes in cross-shore gradient of significant wave height (Fig. 7(f)).

TKE is highest in the surf zone, at the top of the water-column (Fig. 8(a)). Turbulent eddies advect into the water column and offshore. Eddy viscosity is also highest is the region of surf bore propagation (Fig. 8(b)). There is a sharp vertical front in eddy viscosity at the surf break, with large horizontal gradients down to the bottom. The eddy viscosity remains high beyond the middle of the water column in the surf zone and above background near the bottom. Above-background eddy viscosity near the bottom is also predicted offshore of the shallower bar, up to the second bar. Both TKE and eddy viscosity decay rapidly away from the bore, with peak values being an order of magnitude larger than background levels. 


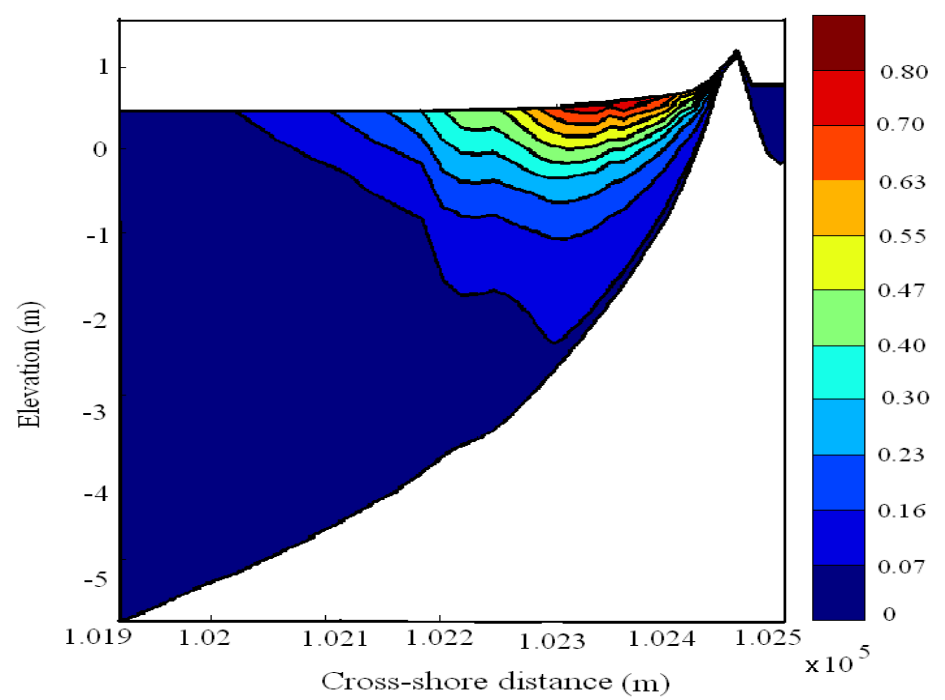

(a)

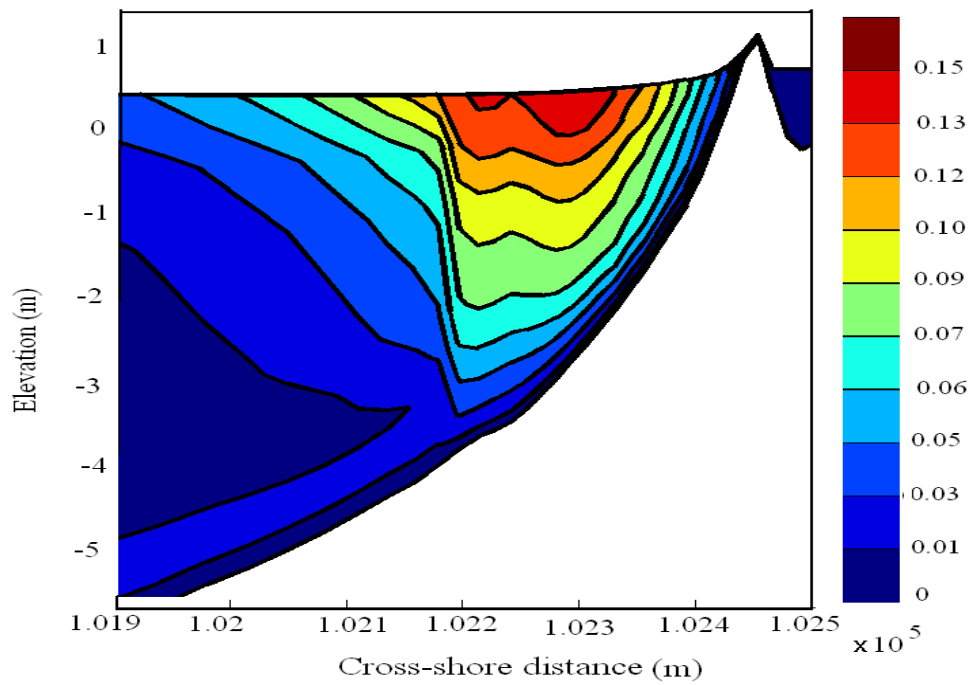

(b)

Fig. 8 (a) TKE $\left(\mathrm{m}^{2} \mathrm{~s}^{-2}\right)$ and (b) eddy viscosity $\left(\mathrm{m}^{2} \mathrm{~s}^{-1}\right)$ for case $1\left(\beta=1: 100, A=2 \mathrm{~m}, \alpha=260^{\circ}, H=2\right.$ $\mathrm{m}$, combined wave and tide, $k-\varepsilon$ turbulence model, $D=200 \mu \mathrm{m})$.

3.2.2 Modeling of nearshore hydrodynamics using different turbulence closure models

Wave- and bed-generated turbulences are key sources of energy for sediment transport in the nearshore area and morphological evolution of the beach. The commonly used, two-equation $k-\varepsilon$ closure has been successful in simulating complex flows such as recirculating and nearshore flows (Lesser et al. 2004, Bakhtyar et al. 2009b). Alternative turbulence models are available for 3D simulations, however. Turbulence in nearshore zones can be simulated using large eddy simulation (LES), where the larger scale turbulence is solved directly by the NS equations and the turbulence 
occurring at a length scale smaller than the computational grid size is solved using a turbulence equation (Christensen 2006). In the $k-L$ model, the mixing length, $L$, is prescribed analytically. The algebraic turbulence model (ATM) is the combination of two zero-order closure schemes: Prandtl's Mixing Length model and the Algebraic closure model (Rodi, 1980). In this section, the results obtained by running the numerical model with the four aforementioned turbulence closure models (cases 1-4) are discussed.

Two-dimensional vertical sections of the cross-shore velocity for all four models are shown in Fig. 9. The results can be separated into two groups within which predictions are comparable: $k-\varepsilon$ and H-LES cases on one side and $k-L$ and ATM cases on the other. Both groups yield different cross-shore beach profiles and nearshore hydrodynamics. Focusing on the hydrodynamics, the $k-\varepsilon$ and H-LES models produce the shear stress layers in the surf zone with high horizontal velocities onshore, at the surface, and offshore, at the bottom (Figs. 9(a) and 9(b)). The surface velocities are more intense for H-LES than for $k-\varepsilon$. The intertidal bar acts as an obstacle to the incoming bore. Contrary to the $k-\varepsilon$ case, the bar remains much below the water surface in the H-LES case and accelerates the flow, probably causing secondary breaking of incoming bores (Fig. 9(b)). A relatively quiescent zone is still observed onshore of the intertidal bar in H-LES predictions. The undertow, immediately offshore of the intertidal bar, is less intense for H-LES than for $k-\varepsilon$, possibly because the beach slope at this cross-shore position is gentler.

Differences in the morphodynamics limit the possibility of comparing the predicted nearshore hydrodynamics between the two groups of turbulence closure models. Yet, several results atypical of the nearshore are observed for the $k-L$ and ATM cases. The $k-L$ model predicts two successive velocity reversals above the intertidal trough, from onshore to offshore and then onshore again (Fig. 9(c)). The steep beach section between the berm and the trough appears to act as a reflective boundary. Most of the undertow is confined to the intertidal trough (Fig. 9(c)). The ATM case shows a strong velocity gradient at the steep beach berm, with intense upward, onshore velocities against the near-vertical wall, as well as a 1-m increase in water elevation in the entire cross-shore section (Fig. 9(d)). Bottom velocities are consistently downward.

Fig. 10 shows, for cases $1-4$, cross-shore variations of (a) $v_{t}$, (b) turbulence dissipation rate (TDR) and (c) TKE, all averaged in both the vertical and longshore directions, as well as (d) spatial cross-shore variation in the maximum water depth (flow set-up) averaged in the longshore direction. Here, again, simulations with $k-\varepsilon$ and H-LES yield similar results while the predictions from $k-L$ and ATM are comparable to each other, and are quite different from the $k$ - $\varepsilon$ and H-LES cases. Starting with $k-\varepsilon$ and H-LES, the surf zone exhibits a broad peak in eddy viscosity (Fig. 10(a)) and in TKE (Fig. 10(c)). The onshore limit of the peaks is better defined than their offshore limit as a result of the longshore variability in surf zone width. In particular, the sharp gradient in eddy viscosity seen in the single cross-shore profile (Fig. 8(a)) is smoothed in the process of longshore averaging. The TDR shows a sharp maximum that is shifted onshore in the H-LES predictions compared with the $k-\varepsilon$ case (Fig. 9(b)). The maximum dissipation occurs at the beach berm or on the intertidal bar when the latter is sufficiently pronounced. The onshore shift observed in the predictions from the H-LES model indicates that the intertidal bar is not as persistent in the longshore direction or as prominent as in the $k-\varepsilon$ case. The latter situation, corresponding to the $k-\varepsilon$ model, is more consistent with existing hydrodynamic understanding (Nielsen 1992, Grasso et al. 2011). The maximum set-up, however, takes place at the intertidal bar in both cases (Figs. 9(a), 9 (b) and 10(d)). A minor set-down is observed at the approach of the shoaling zone. 


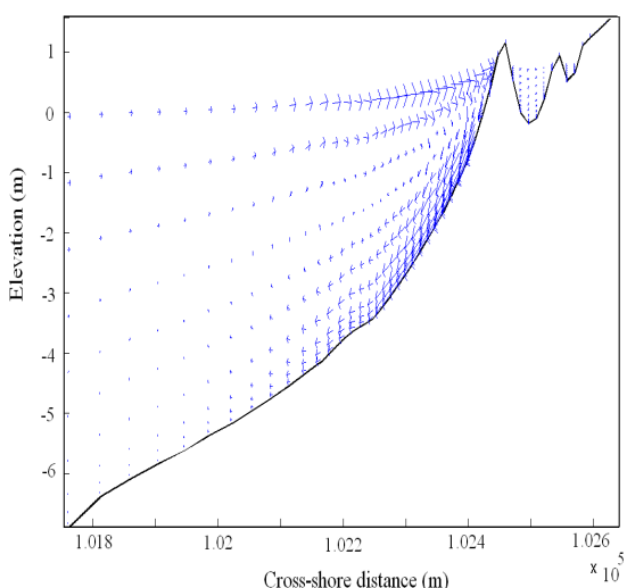

(a)

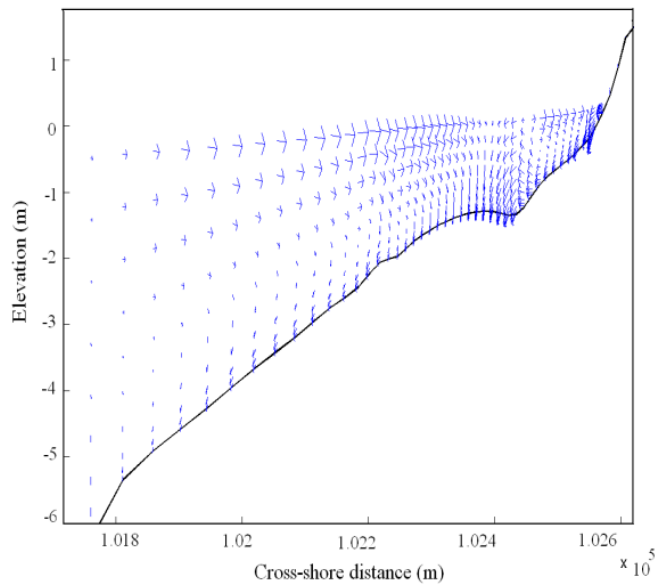

(c)

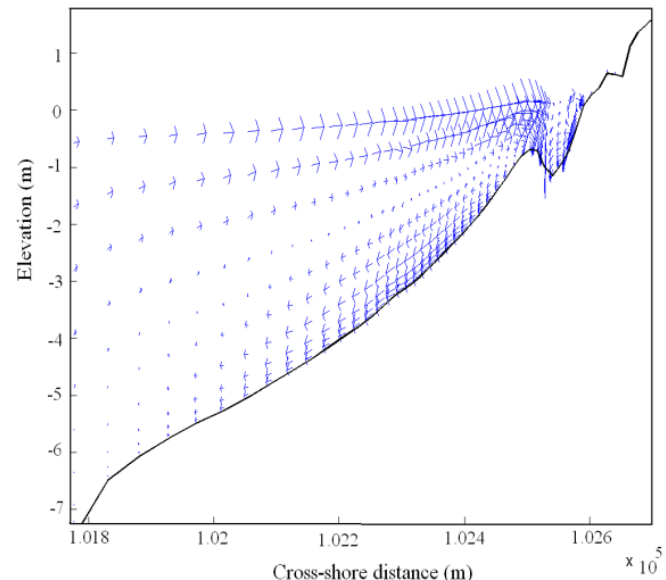

(b)

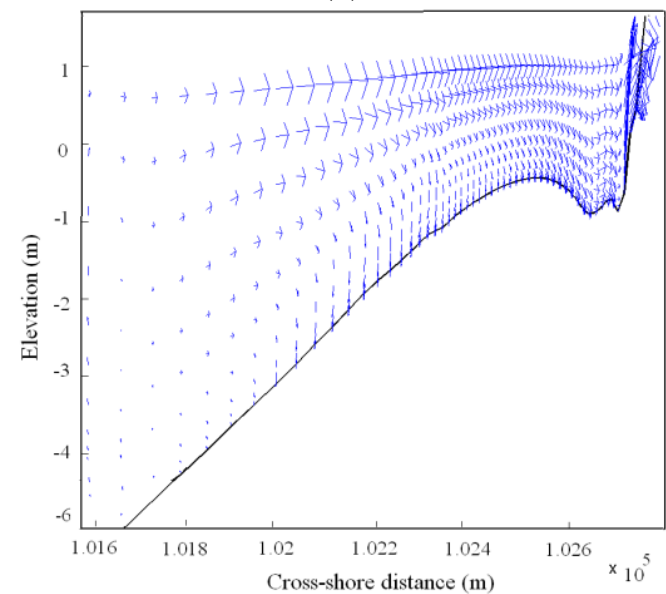

(d)

Fig. 9 Cross-shore velocity and undertow distribution for different turbulence closure models: (a) $k-\varepsilon$, case 1, (b) H-LES, case 2, (c) $k-L$, case 3 and (c) ATM, case 4

The other two closure models ( $k-L$ and ATM) show anomalous cross-shore variations in eddy viscosity and TKE, with a broad maximum located offshore, near the approximate cross-shore position of the closure depth. Turbulence and energy transfer at smaller scales of the flow are predicted to reach a maximum offshore of the shoaling zone. The $k-L$ model still yields a peak in TDR. The TDR peak, located at the cross-shore position of the first velocity reversal over the intertidal trough, is double that of the $k-\varepsilon$ and H-LES models. The ATM model barely shows an increase in TDR near the berm, being an order of magnitude less than in other models. The cross-shore variation in set-up is also somewhat unrealistic in the $k-L$ and ATM models, showing a broad plateau covering the entire surf zone. The trend of the shoreward increase in set-up is negative (the rising part of the curve is concave), while it is positive in the $k$ - $\varepsilon$ and H-LES cases (the rise is concave). Both the $k-L$ and ATM models yield predictions strikingly similar to each other, except for the weak set-down near the closure depth in the $k-L$ case. 


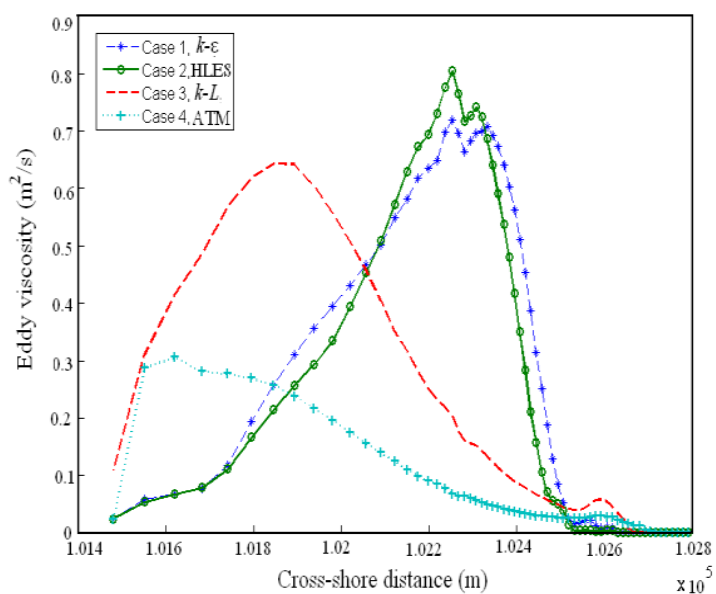

(a)

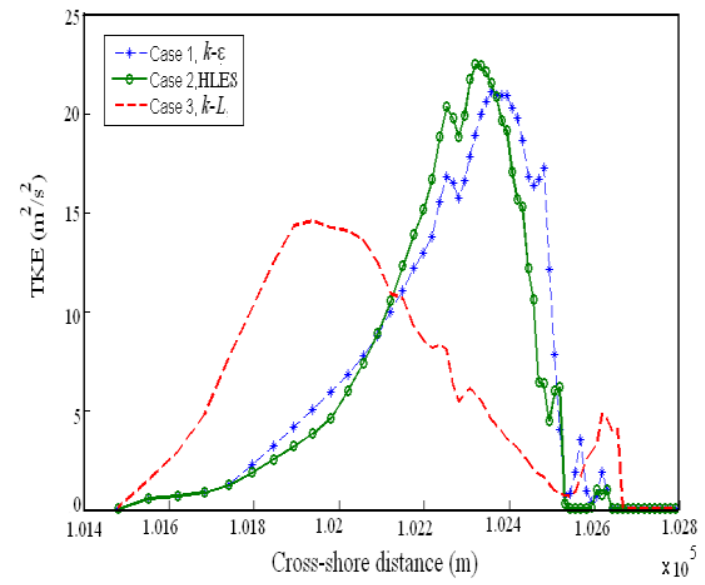

(c)

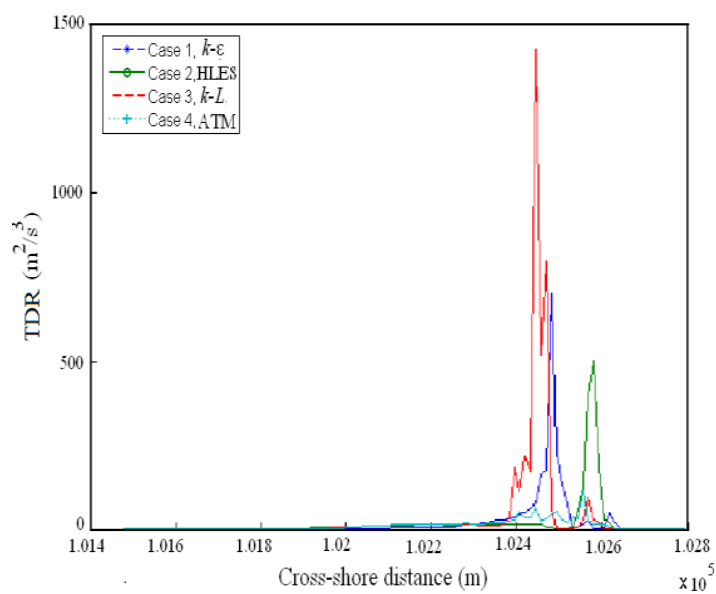

(b)

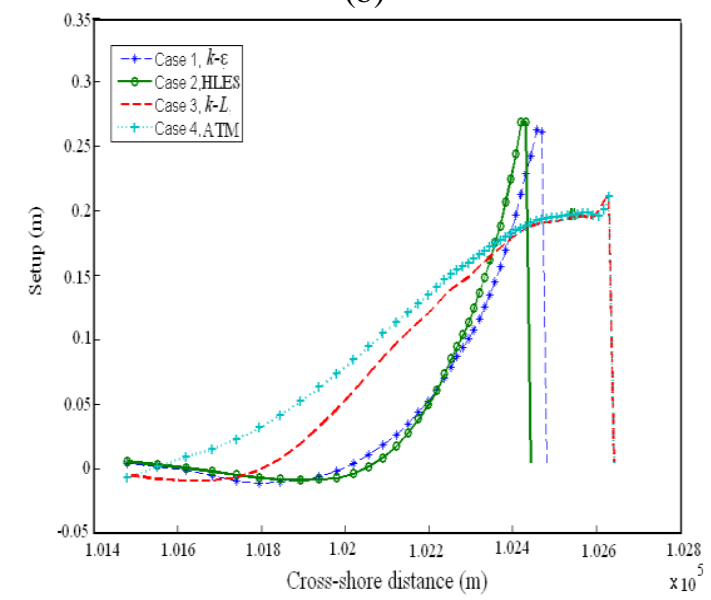

(d)

Fig. 10 Spatial distributions of (a) eddy viscosity, (b) TDR, (c) TKE, and (d) spatial cross-shore variation of maximum water depth (flow setup) in the cross-shore direction for cases 1-4 (different turbulence models: listed in figures). Note that ATM method does not calculate TKE

Generally, the different turbulence closure models yield different numerical predictions for the surf-swash hydrodynamic characteristics. Our purpose here is not to examine in detail these different models, but rather to assess their predictions qualitatively. The results obtained with the $k-\varepsilon$ and H-LES closure models are more consistent with field measurements as well as with the typical theoretical picture of nearshore hydrodynamics than the results obtained with the $k-L$ and ATM models (Lesser at al. 2004). The implementation of LES requires high-fidelity numerical codes, proper treatment of filters and boundary conditions, etc., which were lacking in this study. Therefore, because it is most common in nearshore applications, the $k-\varepsilon$ turbulence closure is used in the remainder of present paper. 


\subsubsection{Hydrodynamics of nearshore zone for different oceanic forcing}

Waves, tides and the currents they induce drive hydrodynamics and foreshore profile changes. This section aims to quantify the individual (cases 5 and 6) and combined (case 1) effects of tides and waves on nearshore hydrodynamics.

Wave action is responsible for the high velocity surface and bottom layers (Fig. 11(b)), which are hardly present in the tide-only case (Fig. 11(c)). Consistently and as expected, energy dissipation, turbulence and set-up are negligible without waves, except for a localized bottom current in a divergence zone at 1-m water depth (Figs. 11(c) and 12(a)-12(c)). In contrast, tidal forcing significantly modifies the action of waves. Such wave and tide interaction has a noticeable effect on the foreshore profile with the formation of the intertidal bar. Without the tide, the maxima in eddy viscosity, TDR, TKE and set-up are shifted shoreward compared with the combined waves and tide case (Fig. 12). Without the intertidal bar and trough in the wave-only case, the onshore limit of the surf zone is displaced shoreward up to the beach berm (Fig. 11(a)). As the bar showing the offshore limit of the surf zone is also displaced shoreward by about the same distance (Fig. 11(a)), the width of the surf zone appears to be maintained. Note that the TDR and set-up are somewhat reduced in the absence of the tide, while eddy viscosity and TKE are augmented slightly (Fig. 12).

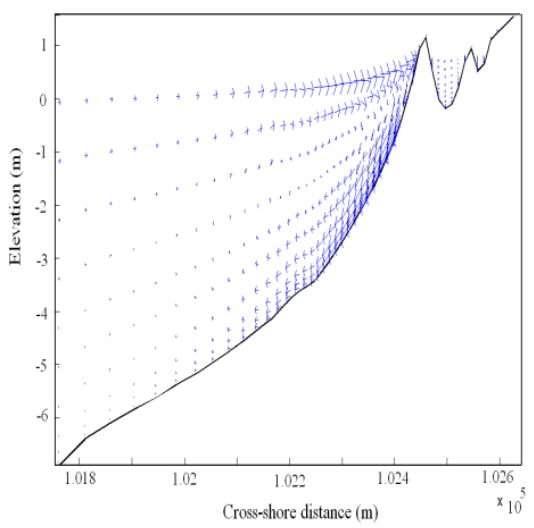

(a)

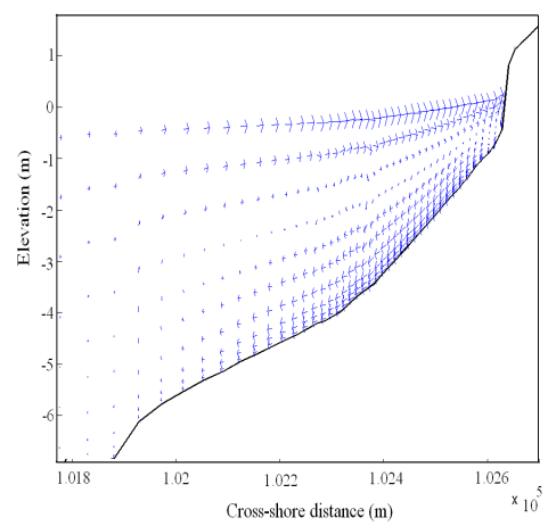

(b)

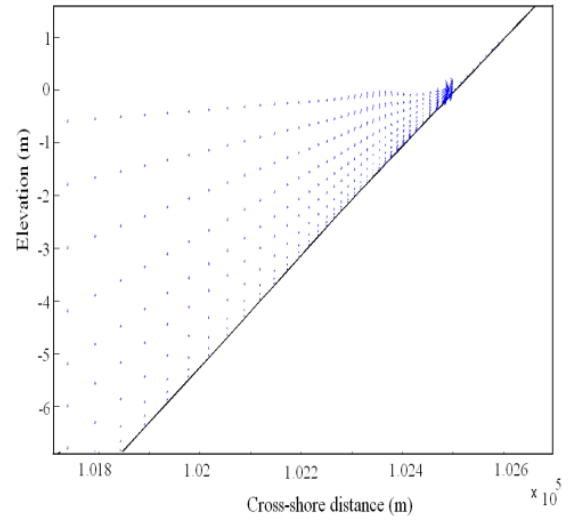

(c)

Fig. 11 Cross-shore velocity and undertow distribution for different oceanic forcing: (a) combined wave and tide, case 1, (b) wave only, case 5 and (c) tide only, case 6 


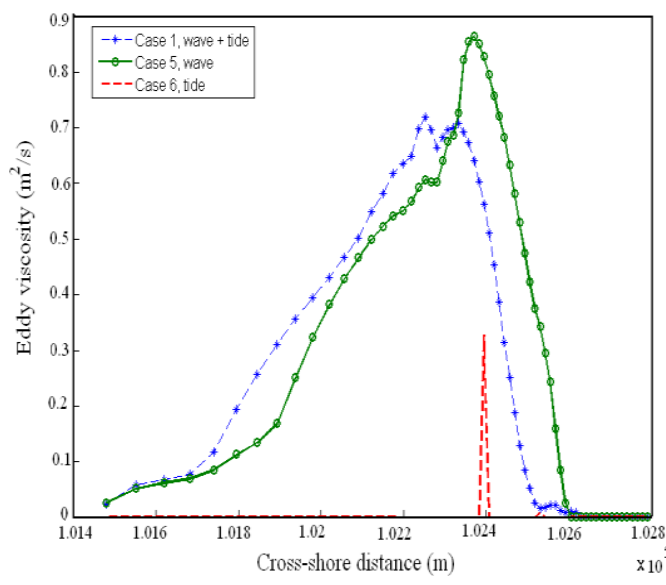

(a)

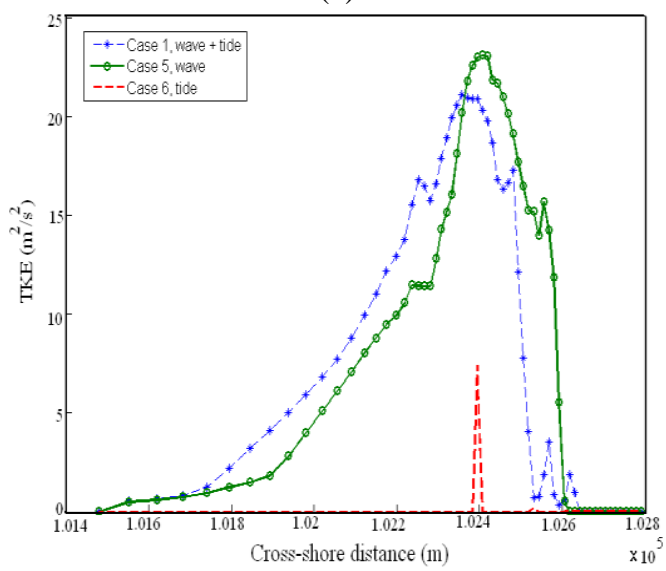

(c)

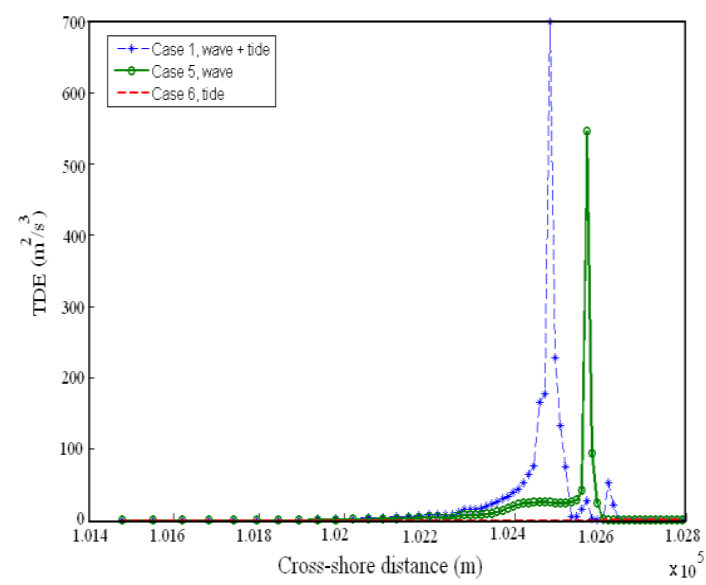

(b)

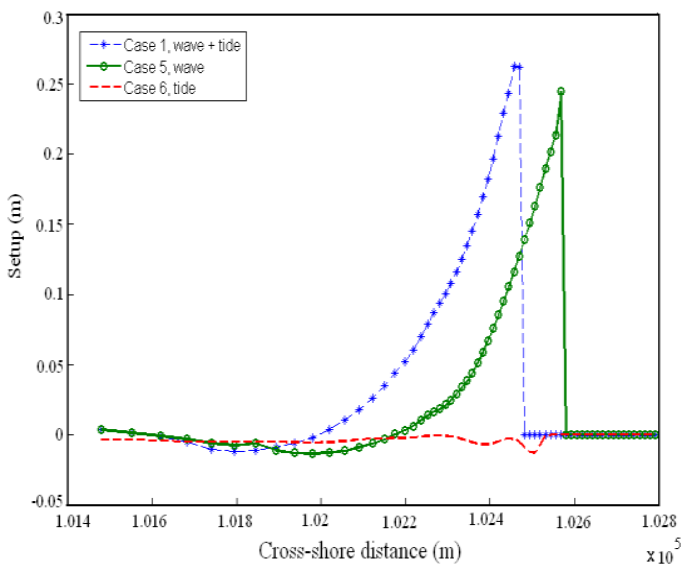

(d)

Fig. 12 Spatial distributions of (a) eddy viscosity, (b) TDR, (c) TKE, and (d) spatial cross-shore variation of maximum water depth (flow setup) in the cross-shore direction for cases 1, 5 and 6 (different oceanic forcing: listed in figures

\subsubsection{Effect of tide and wave characteristics on nearshore hydrodynamics}

Wave and tidal characteristics - wave height, wave angle, and tidal amplitude - control the flow patterns and as a result sediment transport. Here, the predicted nearshore hydrodynamics are investigated numerically under different oceanic forcing characteristics (cases 1,7-15).

In general, increasing the wave height causes a steady increase in the level of the peaks of eddy viscosity, TKE and wave set-up (Figs. 14(a), 14(c), 14(d)). The observed dependence is nearly linear (Bakhtyar et al. 2010a ,b, Feddersen 2012). As peak values increase, an offshore shift of the cross-shore position of the peaks is observed. This offshore shift is more pronounced after the intertidal bar has formed. The spatially integrated TDR is still larger for 2-m waves (Fig. 14(b)). Nearshore turbulence is generated through both free surface (e.g., wave breaking) and bottom (bed shear stress) processes. TDR is very variable and strongly depends on incident wave height but also on other parameters such as tidal range and longshore current magnitude (Feddersen 2012). 


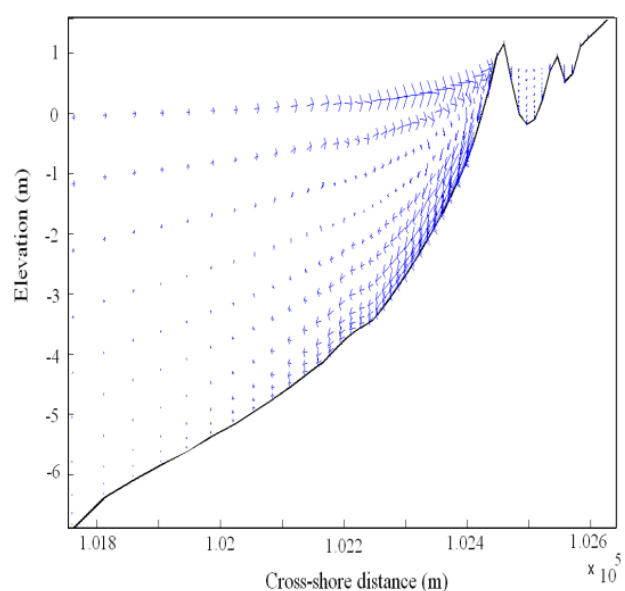

(a)

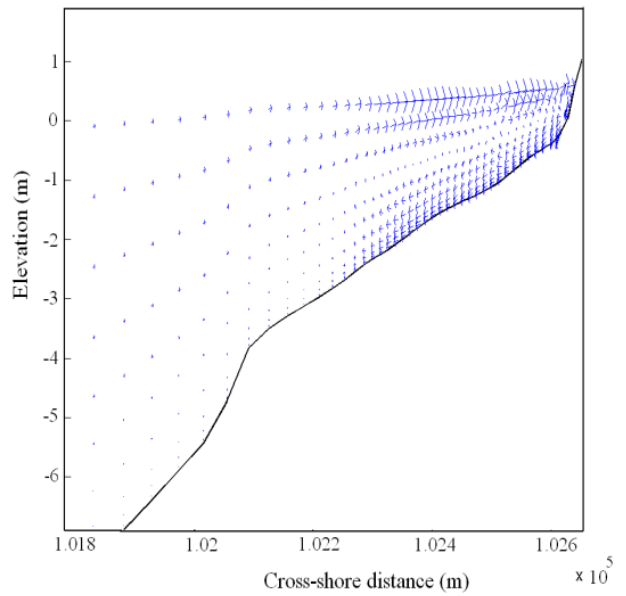

(c)

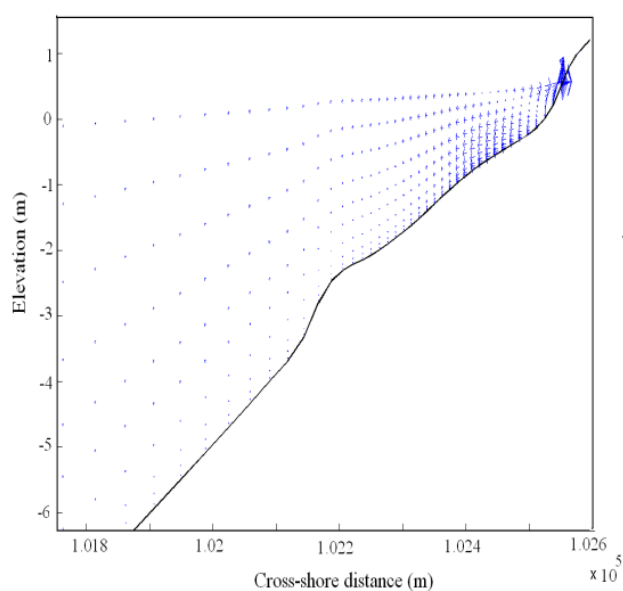

(b)

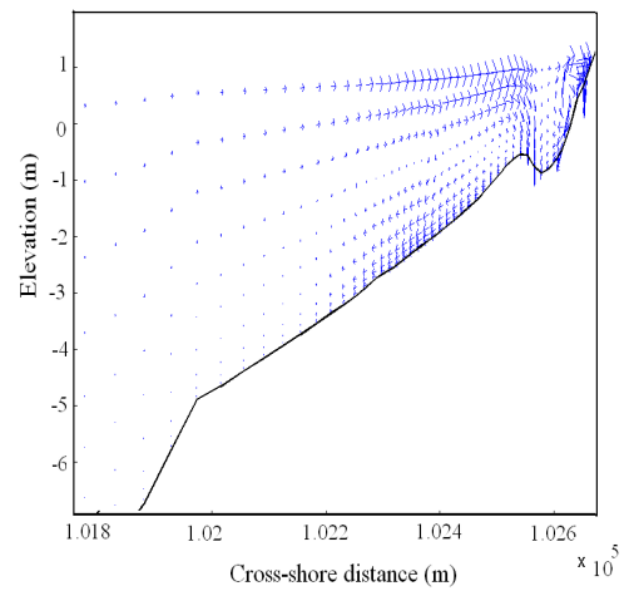

(d)

Fig. 13 Cross-shore velocity and undertow distribution for different wave heights: (a) $H=2 \mathrm{~m}$, case 1 , (b) $H=0.5 \mathrm{~m}$, case 7 , (c) $H=1 \mathrm{~m}$, case 8 , (d) $H=1.5 \mathrm{~m}$, case 9

The normal to the shoreline is oriented at about $275^{\circ}$, clockwise from north. The surf zone circulation, with both onshore flow at the surface and offshore flow at the bottom, is observed for all incident wave directions within $35^{\circ}$ of the shore-normal direction. Velocities are significantly reduced for an incident angle of $240^{\circ}$, compared other directions that were simulated $\left(260^{\circ}, 280^{\circ}\right.$ and $300^{\circ}$ ). Similar predictions of eddy viscosity and TKE are obtained for wave directions making a small angle to the shore-normal direction, $260^{\circ}$ and $280^{\circ}$ (Fig. 16(a) and 16(c)). TDR is smaller for $280^{\circ}$ than $260^{\circ}$ (Fig. 16(b)) and the wave set-up for $280^{\circ}$ waves shows a plateau in the intertidal zone, onshore of the peak (Fig. 16(d)). As wave obliquity increases, the maxima in eddy viscosity ( $240^{\circ}$ only), TDR, TKE and wave set-up are shifted onshore, in relation to the existence of an intertidal bar (see part II). The increase in obliquity enhances the longshore current, which in turn enhances bar formation. Therefore, the change in beach profile modifies the location of the maximum energy dissipation. TDR is an order of magnitude higher for $300^{\circ}$ than other directions. 
For $300^{\circ}$ waves, the eddy viscosity and TKE show an unusual cross-shore profile with high values almost throughout the simulated domain, from the offshore limit of wave action to the shoreline. This is likely due to the strong variability of TDR, which depends on several factors such as wave height, tidal range and longshore current magnitude.

Increasing the tidal amplitude reduces the peaks in eddy viscosity and TKE and spreads them towards the shore (Figs. 18(a) and (c)). This occurs because over time the surf zone moves in the cross-shore direction and covers a larger width (cross-shore wise) of the beach profile, resulting in a kind of spatial averaging. More specifically, the changing tide moves these peaks closer to shore and changes the beach profile, which affects the location of the peaks. Figs.18(b) and (d) shows that the peaks in TDR and wave set-up are shifted shoreward. Tidal amplitudes of 1 and $2 \mathrm{~m}$ yield similar results, except for TDR, where the peak value is double for a 2-m tide compared with other tidal ranges (Fig. 18(b)). The cross-shore velocity distribution shows a reversal in surface velocity over the intertidal bar for a 1-m tide; where the bar is smaller than for the 2-m case.

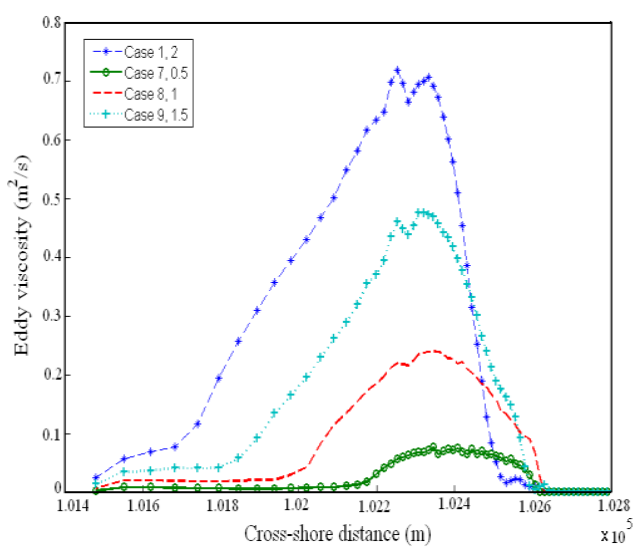

(a)

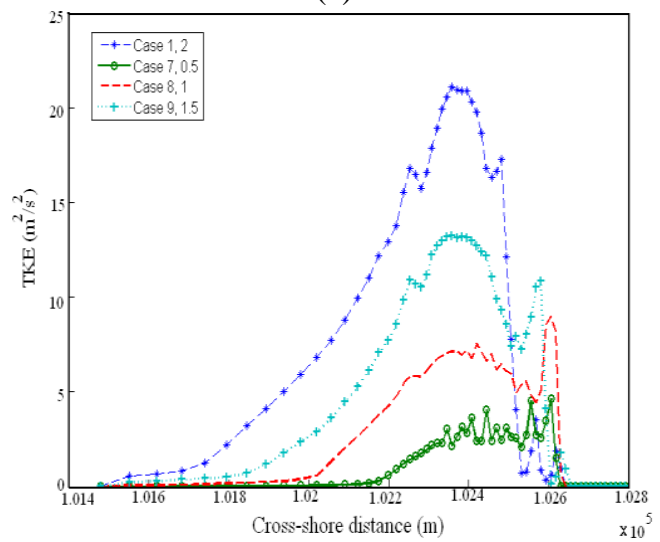

(c)

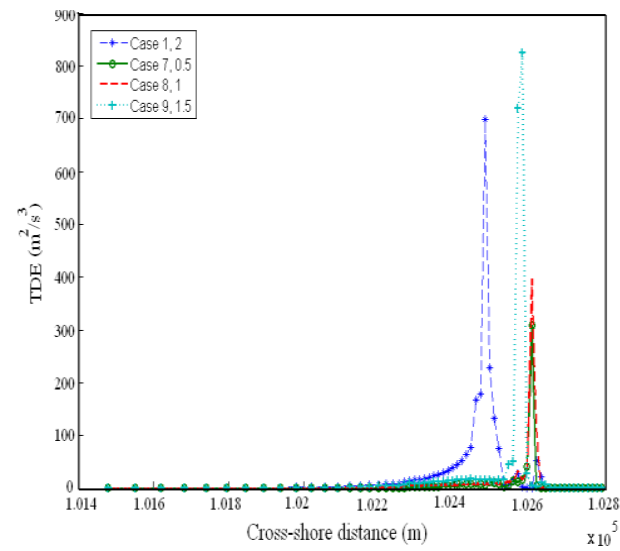

(b)

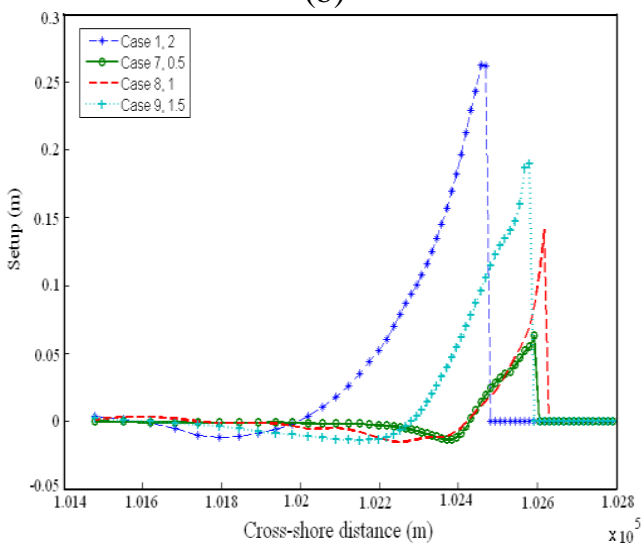

(d)

Fig. 14 Spatial distributions of (a) eddy viscosity, (b) TDR, (c) TKE, and (d) spatial cross-shore variation of maximum water depth (flow setup) in the cross-shore direction for cases 1, 7-9 (different wave heights: listed in figures) 


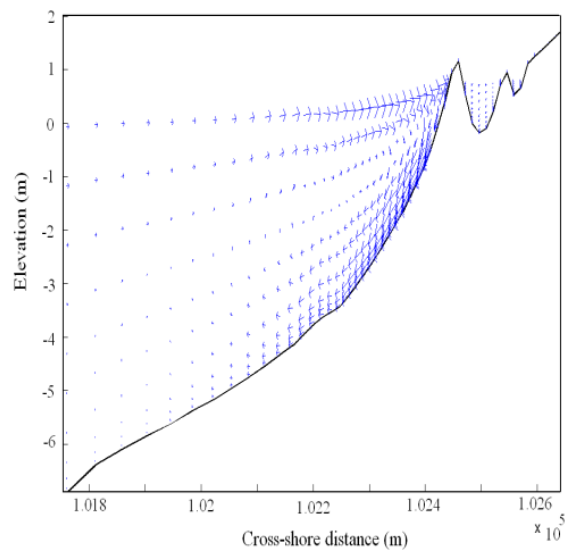

(a)

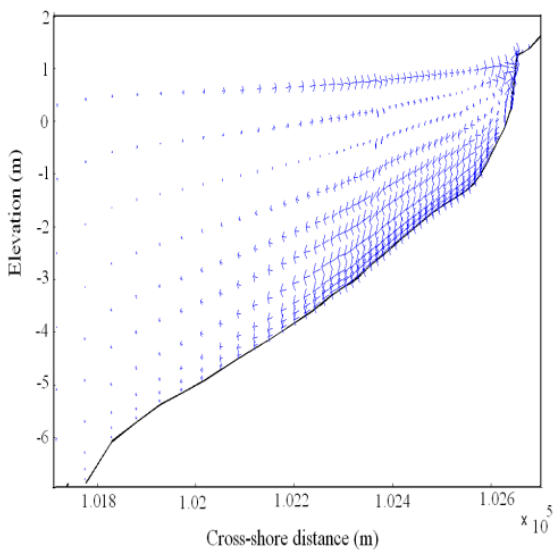

(c)

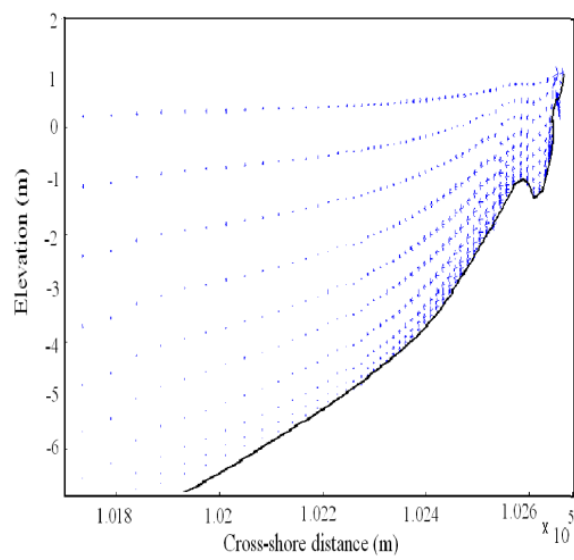

(b)

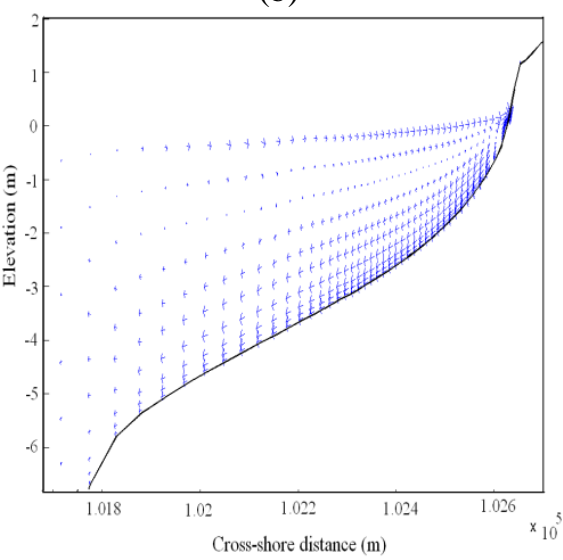

(d)

Fig. 15 Cross-shore velocity and undertow distribution for different wave angles: (a) $\alpha=260^{\circ}$, case 1 , (b) $\alpha=240^{\circ}$, case 10 , (c) $\alpha=280^{\circ}$, case 11 , (d) $\alpha=300^{\circ}$, case 12

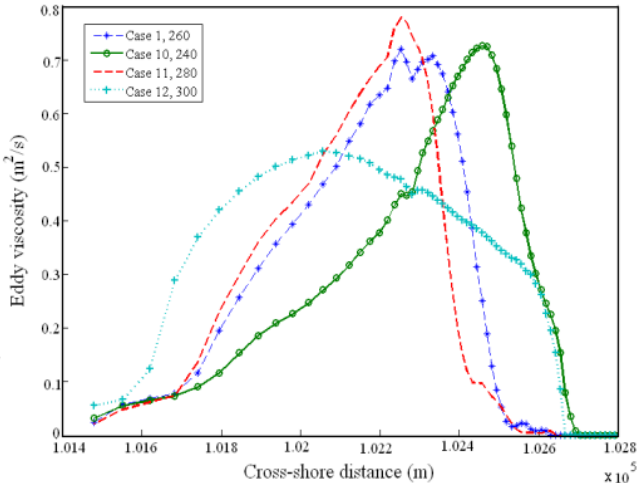

(a)

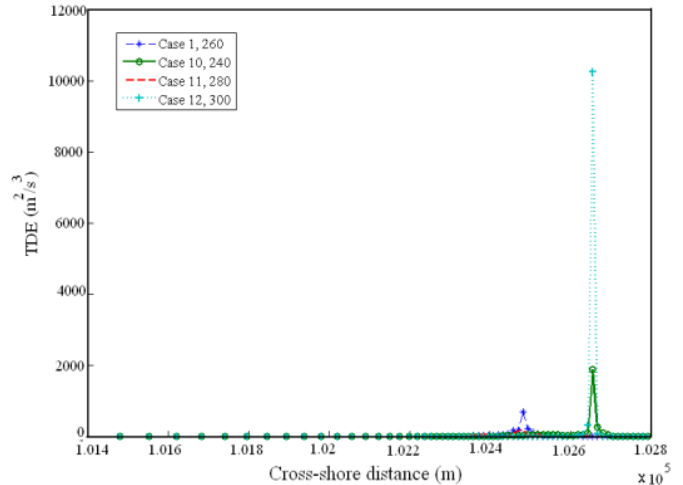

(b)

Continued- 


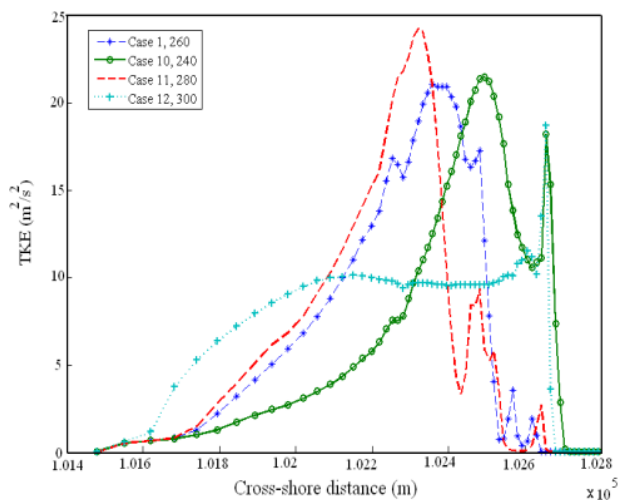

(c)

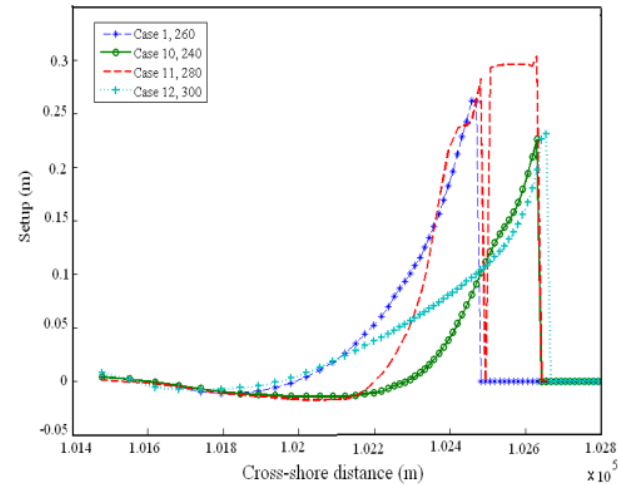

(d)

Fig. 16 Spatial distributions of (a) eddy viscosity, (b) TDR, (c) TKE, and (d) spatial cross-shore variation of maximum water depth (flow setup) in the cross-shore direction for cases 1, 10-12 (different wave angles)

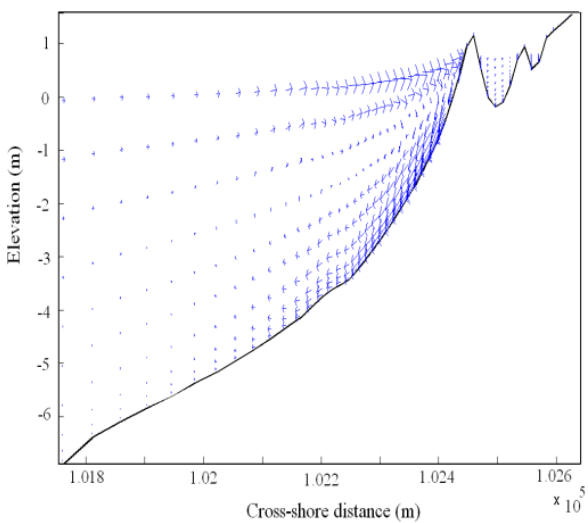

(a)

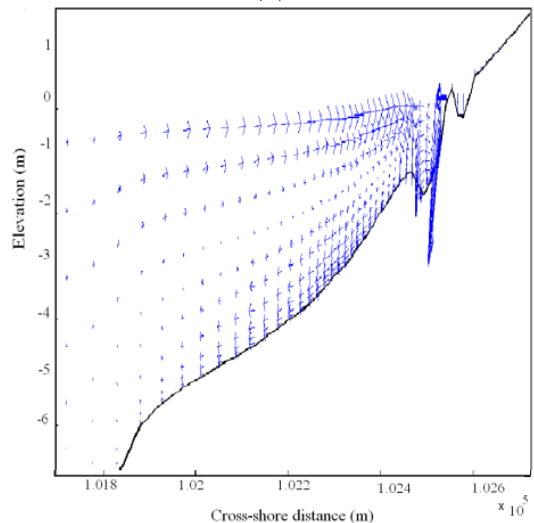

(c)

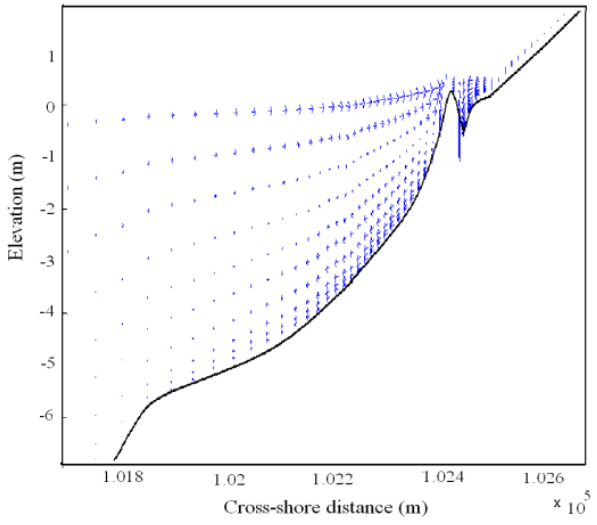

(b)

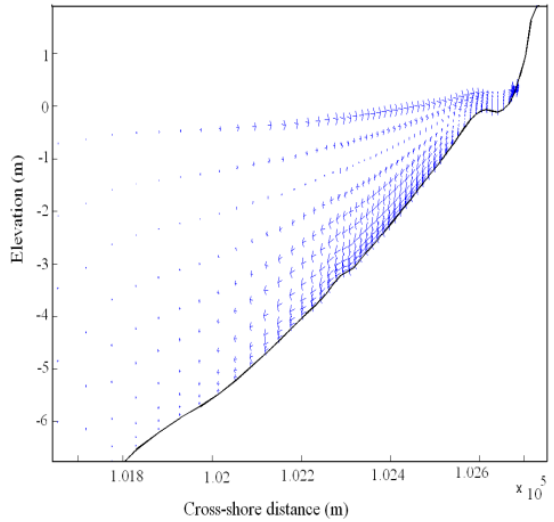

(d)

Fig. 17 Cross-shore velocity and undertow distribution for different tidal ranges: (a) $A=2 \mathrm{~m}$, case 1 , (b) $A$ $=0.5 \mathrm{~m}$, case $13,(\mathrm{c}) A=1 \mathrm{~m}$, case 14 and (d) $A=3 \mathrm{~m}$, case 15 


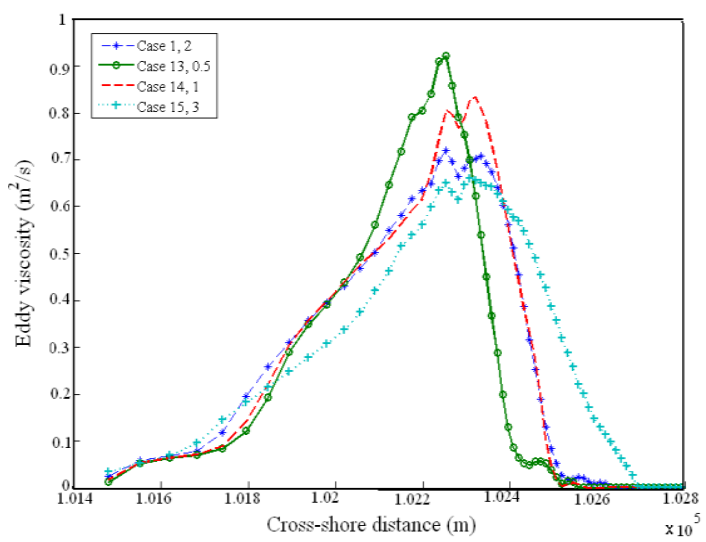

(a)

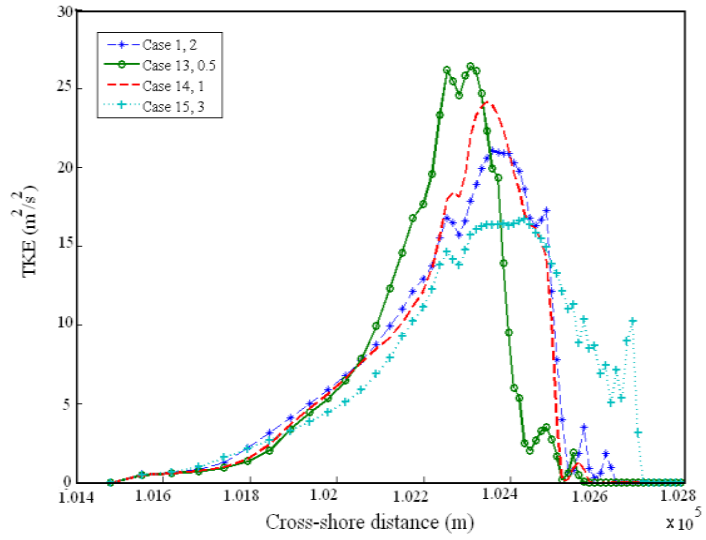

(c)

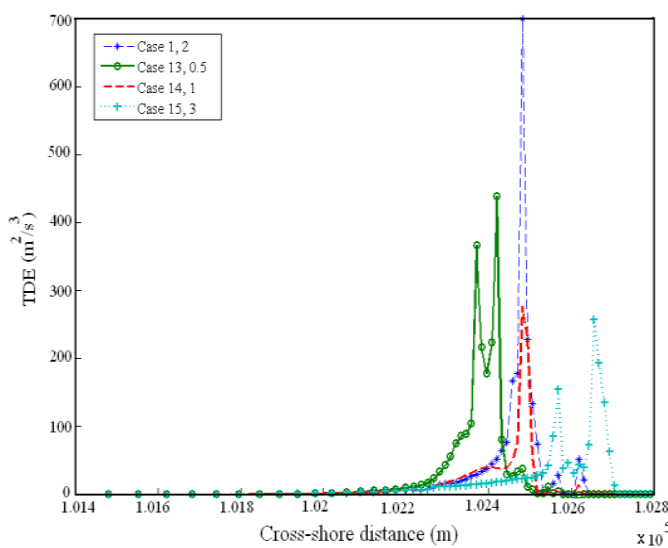

(b)

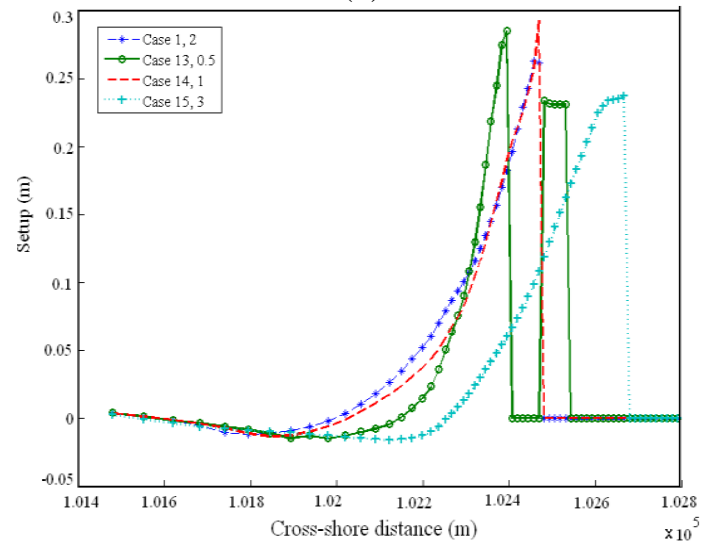

(d)

Fig. 18 Spatial distributions of (a) eddy viscosity, (b) TDR, (c) TKE, and (d) spatial cross-shore variation of maximum water depth (flow setup) in the cross-shore direction for cases 1, 13-15 (different tidal ranges)

\subsubsection{Influence of beach characteristics (grain size and bed slope) on nearshore hydrodynamics}

Beach types and hydrodynamics in the surf zone can be categorized using the non-dimensional surf similarity parameter (Guza and Inman 1975), $\psi$, defined as

$$
\psi=\frac{4 H \pi^{2}}{T^{2}|\vec{g}| \tan ^{2} \beta} .
$$

When $\psi>20$, dissipative conditions occur, while the range for $2.5<\psi<20$ corresponds to intermediate beaches. Intermediate beaches normally have steep slopes and are associated with coarse grain sands and narrow surf zones, while dissipative beaches generally have mild slopes and are related to fine sands and wider surf zones (Miles et al. 2006, Bakhtyar et al. 2010a). In this study, all cases were dissipative, corresponding to the most common type of beaches along the coasts of Netherlands. In addition, numerical studies and field observations have shown that 
sediment size plays an important role on beach hydro- and morphodynamics (Horn et al. 2007, Bakhtyar et al. 2011). Below, the results of numerical experiments for different beach slopes and grain sizes are compared (cases 1, 16-21).

Beach profile steepness modifies the nearshore circulation pattern, significantly enhancing the vertical component of the flow. As the steepness increases, there are several occurrences of plunging flow in the upper half of the water column in the foreshore (Figs. 19(b) and 19(c)). Combined with the usual pattern of onshore surface flow and offshore bottom flow, these downward velocities yield a succession of vortices in the vertical plane, oriented clockwise with the shoreline to the right. The vortices are encapsulated as they would be incomplete on their own, without an upward flow. They cause oscillations of the water surface (Fig. 19). Wave set-up for the 1:75 case (Fig. 20(d)) shows resonant features that could arise from reflection on the steep beach face. The vertical thickness of the undertow is significant (Figs. 19(b) and 19(c)). High vertical velocities are observed just seaward of the abrupt slope break at the offshore limit of wave action, with even a reversal for the 1:75 case (Fig. 19(c)). The transformation of incoming waves as they reach shallow water occurs closer to the shoreline for steeper profiles. Consistently, the peaks in eddy viscosity, TDR, TKE and wave set-up are shifted onshore for steeper slopes (Fig. 20).

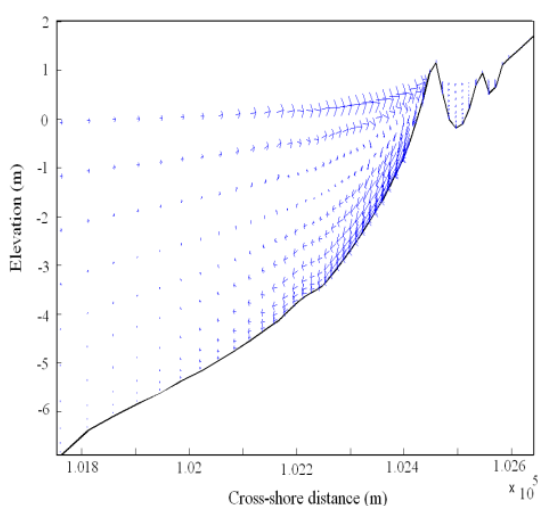

(a)

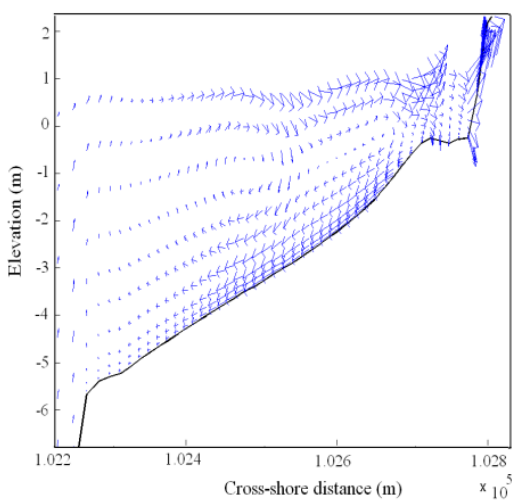

(b)

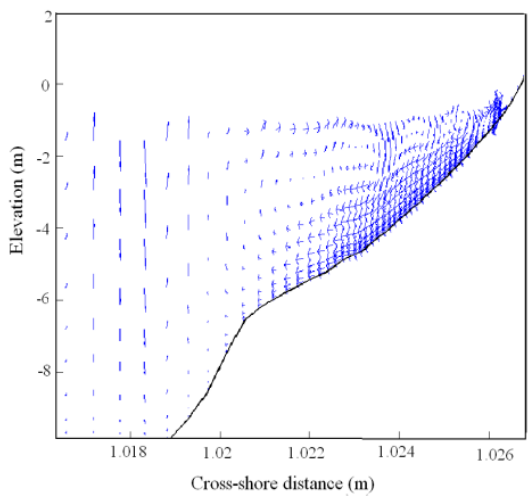

(c)

Fig. 19 Cross-shore velocity and undertow distribution for different bed slopes: (a) $\beta=1: 100$, case 1 , (b) $\beta=1: 50$, case 16 and (c) $\beta=1: 75$, case 17 


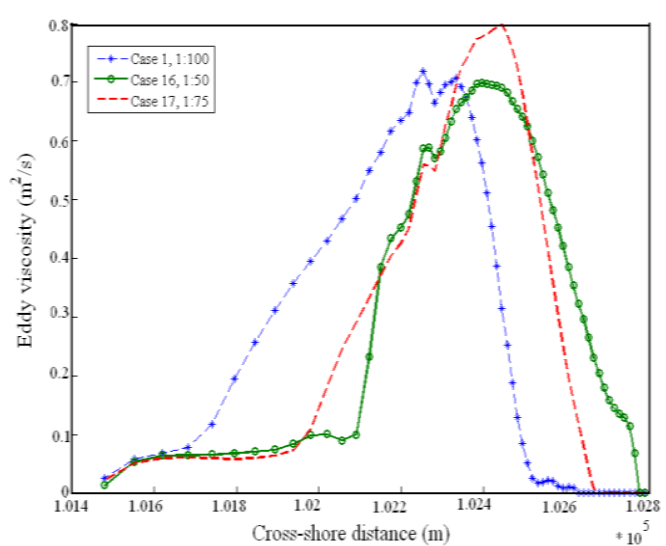

(a)

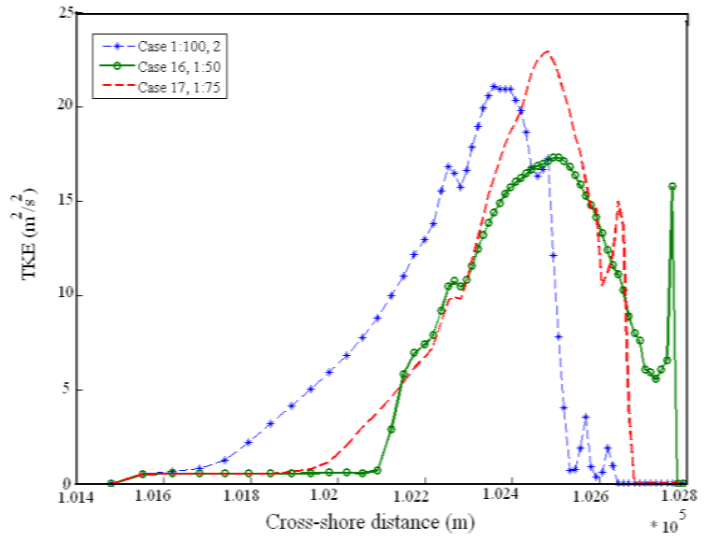

(c)

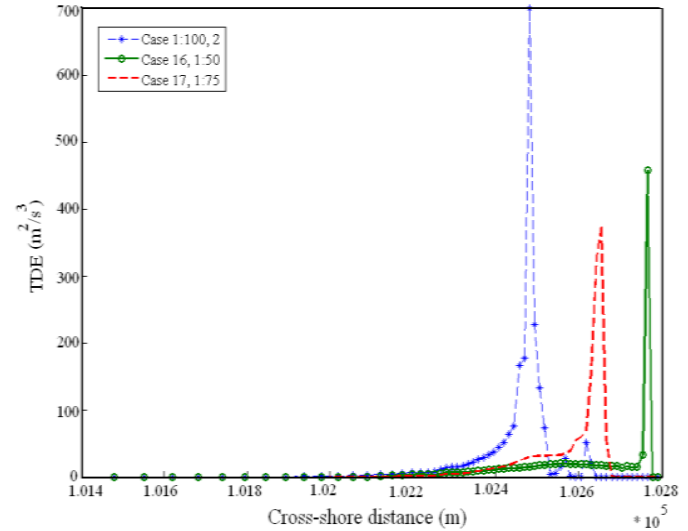

(b)

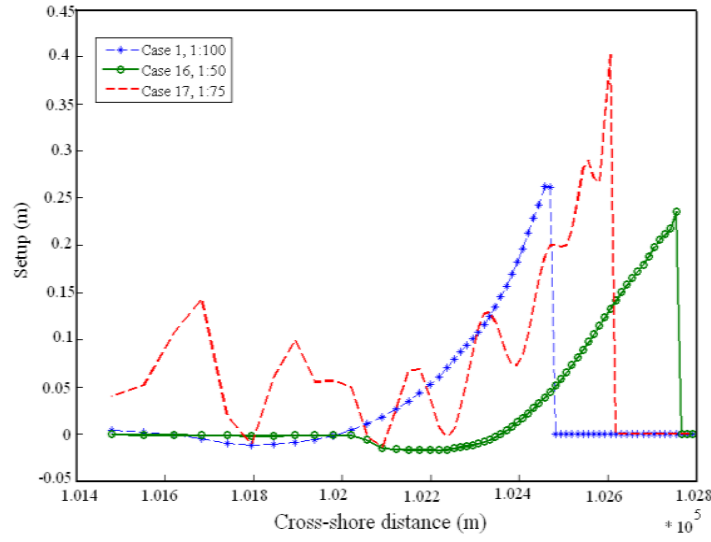

(d)

Fig. 20 Spatial distributions of (a) eddy viscosity, (b) TDR, (c) TKE, and (d) spatial cross-shore variation of maximum water depth (flow setup) in the cross-shore direction for cases 1, 16-17 (different beach slopes)

The interaction between grains and the flow's turbulence has an important effect on the sediment concentration profile and beach morphodynamics (Conley et al. 2008, Absi 2010). Wave motion mobilizes the grains, while turbulence diffuses sediments into the water column. Coarsening of the grain size tends to generate more complex nearshore hydrodynamic patterns. The existence of suspended sediment in the water column induces a stabilization of the turbulence, since mixing of the flow now needs extra energy and changes the velocity and sediment profiles (Fredsoe 1993). The observed reversals of the horizontal velocity (Figs. 21(b) and 21(c)) and fluctuations in the vertical component of the offshore bottom flow (Figs. 21(c) and 21(d)) result from the coupling between nearshore flow and morphodynamics. The transport of coarser grains is associated with morphological disturbances to the foreshore profile. High values of eddy viscosity, TKE and wave set-up are spread offshore for coarser grain sizes, with small wavelength fluctuations superimposed over the peak. The TDR is an order of magnitude smaller for $1000-\mu \mathrm{m}$ grains compared with other cases, again due to the turbulence damping by the presence of sediments, which restricts the suspension of the sediment in the upper part of the water column. 
The sediment inhibits turbulence transport near the bed, decreases the boundary layer thickness, and reduces the diffusion of sediment into the water column by lowering the TKE (Lamb et al. 2004, Conley et al. 2008).

\section{Conclusions}

Nearshore hydrodynamics were analyzed under a range oceanic forcing conditions through 3D numerical experiments performed using a comprehensive, process-based model. The results were consistent with existing understanding of surf and swash zone processes and mostly showed good agreement with field measurements. The model is capable of simulating the important hydrodynamic aspects such as undertow, wave breaking, circulation and rip-current patterns generated by radiation stresses and longshore variability in wave heights.

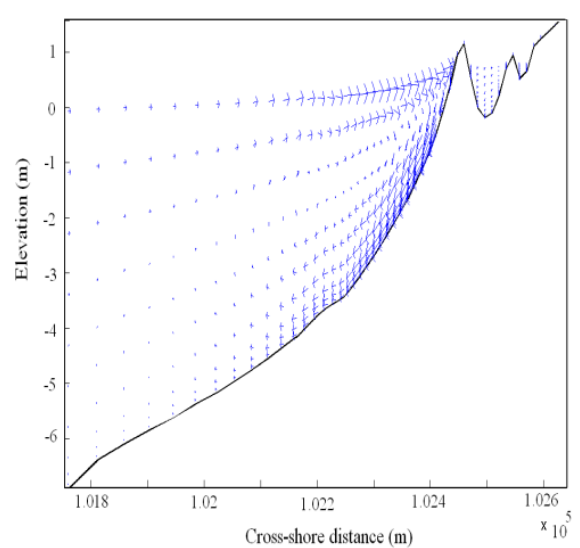

(a)

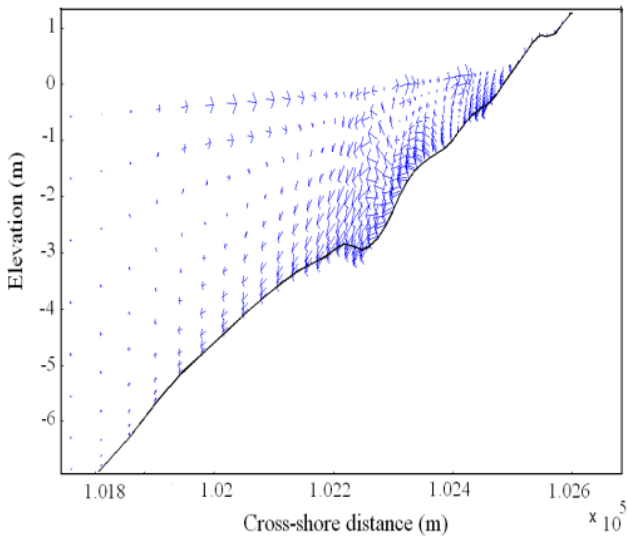

(c)

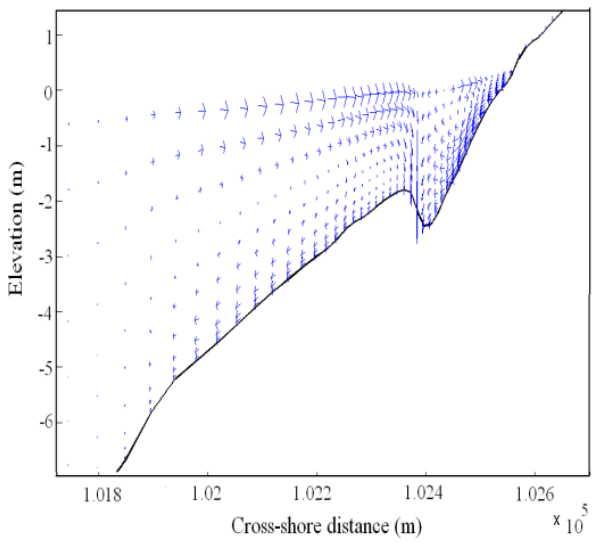

(b)

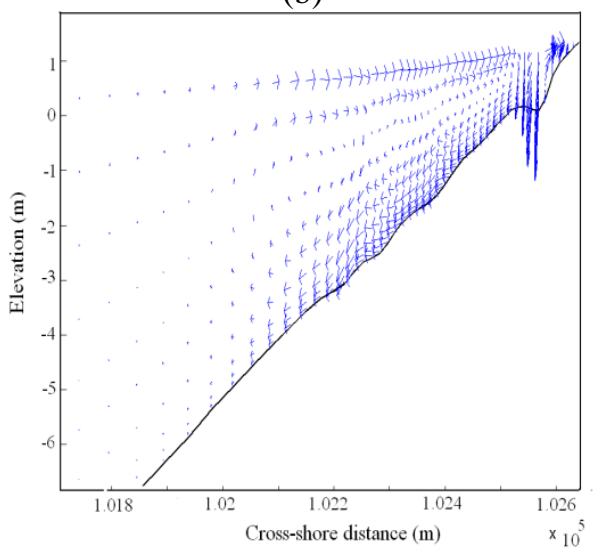

(d)

Fig. 21 Cross-shore velocity and undertow distribution for different bed grain sizes: (a) $D=200 \mu \mathrm{m}$, case 1, (b) $D=500 \mu \mathrm{m}$, case 18 , (c) $D=800 \mu \mathrm{m}$, case 19 and (d) $D=1000 \mu \mathrm{m}$, case 20 
The results obtained with the $k-\varepsilon$ and H-LES closure models are more consistent with field measurements of nearshore hydrodynamics than the results obtained from other turbulence models. TKE, as well as vertical and horizontal velocity components, are highest in the surf zone, at the top of the water-column and below the wave crest. Turbulent eddies are advected into the water column and offshore. The eddy viscosity is also highest in the region of surf bore propagation. Both TKE and eddy viscosity decay rapidly away from the bore, with peak values being an order of magnitude larger than background levels. In addition, increasing the wave height causes a steady increase in the level of the peaks of eddy viscosity and TKE, while increasing the tidal amplitude reduces these peaks.

Without the tide, the maxima in eddy viscosity, TDR, TKE and set-up are shifted shoreward compared with the combined waves and tide case. The TDR and set-up are reduced in the absence of the tide, while eddy viscosity and TKE are augmented somewhat. As wave obliquity increases, the maxima in eddy viscosity, TDR, TKE and wave set-up are shifted onshore, in relation to the existence of an intertidal bar. High values of eddy viscosity, TKE and wave set-up are spread offshore for coarser grain sizes, with small wavelength fluctuations superimposed over the peak.

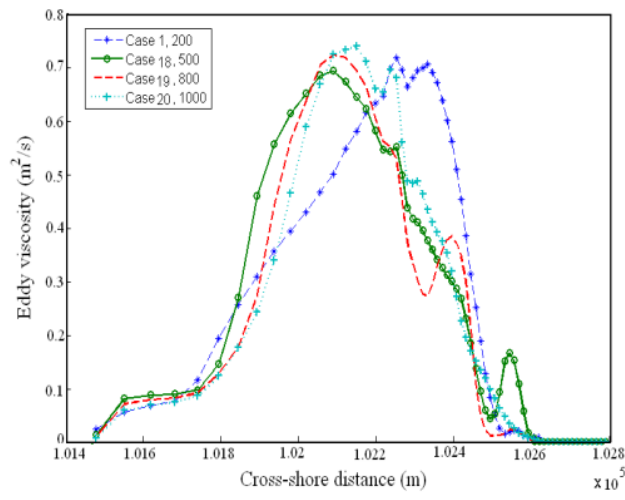

(a)

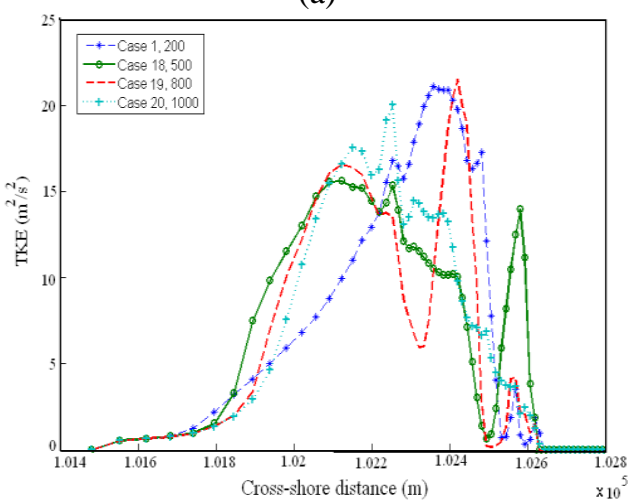

(c)

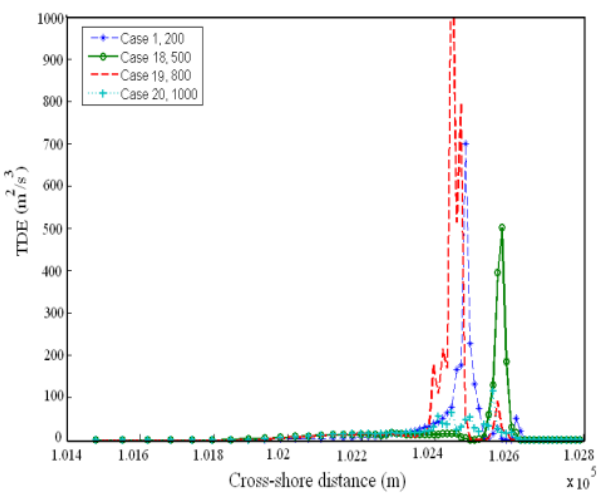

(b)

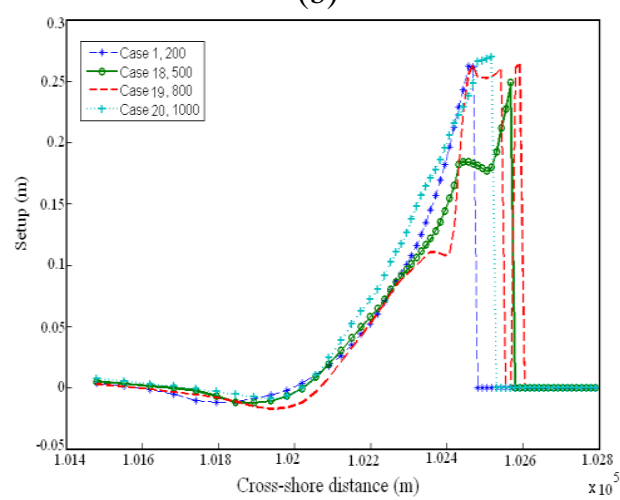

(d)

Fig. 22 Spatial distributions of (a) eddy viscosity, (b) TDR, (c) TKE, and (d) spatial cross-shore variation of maximum water depth (flow setup) in the cross-shore direction for cases 1, 18-20 (different bed grain sizes, listed in figures) 
Numerical results showed that while the angle of incoming waves is large or bed slope is uniform, rips are not generated on a long straight beach under forcing by monochromatic waves. This is consistent with current understanding of nearshore processes since rip currents are believed to be associated with edge waves (Guza and Inman 1975, Thornton et al. 2007). However, in the validation case, the morphological context is shown to induce rips under monochromatic waves. The results show the relation between the circulation and the seabed morphology, where the low relief area in the inshore region corresponds to the longshore position where the water is funneled offshore. The local recirculation inshore of the longshore current causes a transient offshore shift and the strengthening of the longshore current. The cross-shore excursion of the longshore current is associated with enhanced shear stress in the nearshore region.

The coupling between flow and wave solver for 3D hydro- and morphodynamics simulation at field scale was validated, and reasonably good agreement with the existing physical understanding was achieved. In summary, we tried to create a virtual reality model: "we reproduce in the best possible detail the geometry, sedimentology, bathymetry, 3D flow, wave and sediment processes and simulate the evolution of the sea bed and associated processes under various future scenarios" (Roelvink and Reniers 2012). In addition, as this study is comprehensive and we can simulate at field scale most processes induced by various oceanic forcing and beach characteristics in the surf and swash zones, it allows us to use this model as a numerical laboratory (i.e., realistic analogue), with which we can investigate processes and effects in relative isolation.

\section{Acknowledgments}

Support of the Swiss National Foundation (SNF 200021-135322) is acknowledged.

The authors would like to thank Dr. N. Le Dantec for his careful review of the manuscript and the suggestions he made.

\section{References}

Absi, R. (2010), “Concentration profiles for fine and coarse sediments suspended by waves over ripples: An analytical study with the 1-DV gradient diffusion model”, Adv. Water Resour., 33(4), 411-418.

Allard, R., Dykes, J., Hsu, Y.L., Kaihatu, J. and Conley, D. (2008), “A real-time nearshore wave and current prediction system", J. Marine. Syst., 69(1-2), 37-58.

Apotsos, A., Jaffe, B. and Gelfenbaum, G. (2011), "Wave characteristic and morphologic effects on the onshore hydrodynamic response of tsunamis", Coast. Eng., 58(11), 1034-1048.

Austin, M.J. and Masselink, G. (2006), "Observations of morphological change and sediment transport on a steep gravel beach", Mar. Geol., 229(1-2), 59-77.

Bakhtyar, R., Barry, D.A., Li, L., Jeng, D.S. and Yeganeh-Bakhtiary, A. (2009a), "Modeling sediment transport in the swash zone: A review", Ocean Eng., 36, 767-783.

Bakhtyar, R., Barry, D.A., Yeganeh-Bakhtiary, A. and Ghaheri, A. (2009b), "Numerical simulation of surf-swash zone motions and turbulent flow", Adv. Water Resour., 32(2), 250-263.

Bakhtyar, R., Ghaheri, A., Yeganeh-Bakhtiary, A. and Barry, D.A. (2009c), "Process-based model for nearshore hydrodynamics, sediment transport and morphological evolution in the surf and swash zones", Appl. Ocean Res., 31(1), 44-56.

Bakhtyar, R., Yeganeh-Bakhtiary, A, Barry, D.A. and Ghaheri, A. (2009d), "Euler-Euler coupled two-phase flow modeling of sheet flow sediment motion in nearshore", J. Coast. Res., 56, 467-471.

Bakhtyar, R., Yeganeh-Bakhtiary, A., Barry, D.A. and Ghaheri, A. (2009e), "Two-phase hydrodynamic and 
sediment transport modeling of wave-generated sheet flow", Adv. Water Resour., 32(8), 1267-1283.

Bakhtyar, R., Barry, D.A., Yeganeh-Bakhtiary, A., Li, L., Parlange, J.Y. and Sander, G.C. (2010a), "Numerical simulation of two-phase flow for sediment transport in the inner surf and swash zones", $A d v$. Water Resour., 33(3), 277-290.

Bakhtyar, R., Razmi, A.M., Barry, D.A., Yeganeh-Bakhtiary, A. and Zou, Q.P. (2010b), "Air-water two-phase flow model of turbulent surf and swash zone wave motions", Adv. Water Resour., 33(12), 1560-1574.

Bakhtyar, R., Brovelli, A., Barry, D.A. and Li, L. (2011), "Wave-induced watertable fluctuations, sediment transport and beach profile change: Modeling and comparison with large-scale laboratory experiments", Coast. Eng., 58(1), 103-118.

Bakhtyar, R., Barry, D.A. and Brovelli, A. (2012a), "Numerical experiments on interactions between wave motion and variable-density coastal aquifers", Coast. Eng., 60, 95-108.

Bakhtyar, R., Barry, D.A. and Kees, C.E. (2012b), "Numerical experiments of breaking waves on contrasting beaches using a two-phase flow method", Adv. Water Resour., 48, 68-78.

Bakhtyar, R., Brovelli, A., Barry, D.A., Robinson, C. and Li, L. (2013a), "Transport of variable-density solute plumes in beach aquifers in response to oceanic forcing", Adv. Water Resour., 53, 208-224.

Bakhtyar, R., Razmi, A. Barry, D.A., Kees, C.E., Yeganeh-Bakhtiary, A. and Miller, C.T. (2013b), "Two-phase flow modeling of the influence of wave shapes and bed slope on nearshore hydrodynamics", J. Coastal. Res., I65, 159-164.

Choi, D.Y. and Wu, C.H. (2006), "A new efficient 3D non-hydrostatic free-surface flow model for simulating water wave motions", Ocean Eng., 33(5-6), 587-609.

Christensen, E.D. (2006), "Large eddy simulation of spilling and plunging breakers", Coast. Eng., 53(5-6), 463-485.

Conley, D.C., Falchetti, S., Lohmann, I.P. and Brocchini, M. (2008), "The effects of flow stratification by non-cohesive sediment on transport in high-energy wave-driven flows", J. Fluid Mech., 610, 43-67.

Dastgheib, A., Roelvink, J.A. and Wang, Z.B. (2008), "Long-term process-based morphological modeling of the Marsdiep Tidal Basin", Mar. Geol., 256(1-4), 90-100.

Dastgheib, A. (2012), Long-term Process-based Morphological Modelling of Large Tidal Basins PhD thesis, 978-1-138-00022-3UNESCO-IHE Institute for Water Education.

Delft3D-Flow User Manual, (2009), Version: 3.15, Revision: 17474, http://delftsoftware.wldelft.nl/index.php?option=com_docman\&task=cat_view\&gid=39\&Itemid=61, last accessed 1 October 2015.

Elfrink, B. and Baldock, T.E. (2002), "Hydrodynamics and sediment transport in the swash zone: A review and perspectives", Coast. Eng., 45(3-4), 149-167.

Elias, E.P.L., Cleveringa, J., Buijsman, M.C., Roelvink, J.A. and Stive, M.J.F. (2006), "Field and model data analysis of sand transport patterns in Texel Tidal inlet (the Netherlands)", Coast. Eng., 53(5-6), 505-529.

Elias, E.P.L., Walstra, D.J.R., Roelvink, J.A., Stive, M.J.F. and Klein, M.D. (2000), "Hydrodynamic validation of Delft3D with field measurements at Egmond", Proceedings of the $27^{\text {th }}$ International Conference on Coastal Engineering, (Ed., Billy L. Edge), Sydney, Australia.

Elias, E.P.L. (1999), The Egmond Model: Calibration, validation and evaluation of Delft3D-MOR with field measurements, MSc thesis, Delft University of Technology, The Netherlands. http://resolver.tudelft.nl/uuid:4764c864-12ba-4759-ae13-ee1c3170dfff, last accessed 1 October 2015.

Feddersen, F. (2012), "Observations of the surf-zone turbulent dissipation rate", J. Phys. Oceanogr., 42(3), 386-399.

Fredsoe, J. (1993), "Modelling of non-cohesive sediment transport processes in the marine environment", Coast. Eng., 21, 71-103.

Geleynse, N., Storms, J.E.A., Stive, M.J.F., Jagers, H.R.A. and Walstra, D.J.R. (2010), "Modeling of a mixed-load fluvio-deltaic system", Geophys. Res. Lett., 37, L05402, doi:10.1029/2009GL042000.

Geleynse, N., Storms, J.E.A., Walstra, D.J.R., Jagers, H.R.A., Wang, Z.B. and Stive, M.J.F. (2011), "Controls on river delta formation; insights from numerical modeling", Earth Planet. Sci. Lett., 302(1-2), 217-226. 
Grasso, F., Michallet, H. and Barthélemy, E. (2011), "Sediment transport associated with morphological beach changes forced by irregular asymmetric, skewed waves", J. Geophys. Res., 116, C03020, doi:10.1029/2010JC006550.

Guza, R.T., Inman, D.L. (1975), "Edge waves and beach cusps”, J. Geophys. Res., 80, 2997-3012.

Haas, K.A., Svendsen, I.A., Haller, M.C. and Zhao, Q. (2003), "Quasi-three dimensional modeling of rip current systems", J. Geophys. Res., 108, 3217, doi:10.1029/2002JC001355.

Horn, D. and Li, L. (2006), "Measurement and modeling of gravel beach groundwater response to wave run-up: Effects on beach profile changes", J. Coastal. Res., 22(5), 1241-1249.

Horn, D.P., Baldock, T.E. and Li, L. (2007), "The influence of groundwater on profile evolution of fine and coarse sand beaches", Proceedings of the Coastal Sediments '07, ASCE, New Orleans, USA.

Hsu, Y.L., Dykes, J.D., Allard, R.A. and David, D.W. (2008), Validation test report for Delft3D. NRL memorandum report, NRL/MR/7320-08-9079, 42 pp., Naval Research Laboratory, Stennis Space Center, Mississippi, USA.

Hu, K., Ding, P., Wang, Z. and Yang, S. (2009), “A 2D/3D hydrodynamic and sediment transport model for the Yangtze Estuary", China J. Mar. Sys., 77, 114-136.

Karambas, T.V. (2006), "Prediction of sediment transport in the swash zone by using a nonlinear wave model”, Cont. Shelf Res., 26(5), 599-609.

Kumar, V.S., Anand, N.M., Chandramohan, P. and Naik, G.N. (2003), "Longshore sediment transport rate Measurement and estimation, central west coast of India", Coast. Eng., 48, 95-109.

Lamb, M.P., D’Asaro, E. and Parsons, J.D. (2004), "Turbulent structure of high-density suspensions formed under waves", J. Geophys. Res., 109, C12026, doi:10.1029/2004JC002355.

Larson, M., Kubota, S. and Erikson, L. (2004), "Swash-zone sediment transport and foreshore evolution: Field experiments and mathematical modeling", Mar. Geol., 212(1-4), 61-80.

Lesser, G.R., Roelvink, J.A., Van Kester, J.A.T.M. and Stelling, G.S. (2004), "Development and validation of a three-dimensional model", Coast. Eng., 51, 883-915.

Li, L., Barry, D.A., Pattiaratchi, C.B. and Masselink, G. (2002), "BeachWin: Modelling groundwater effects on swash sediment transport and beach profile changes", Environ. Modell. Softw., 17(3), 313-320.

Longuet-Higgins, M.S. (1970), "Longshore currents generated by obliquely incident sea waves", J. Geophys. Res., 75, 6778-6789.

MacMahan, J.H., Thornton, Ed.B. and Reniers, Ad.J.H.M. (2006), "Rip current review", Coast. Eng., 53(2-3), 191-208.

Malvarez, G.C. and Cooper, A. (2000), "A whole surf zone modelling approach as an aid to investigation of nearshore and coastal morphodynamics", J. Coastal. Res., 16(3), 800-815.

Masselink, G., Evans, D., Hughes, M.G. and Russell, P.E. (2005), "Suspended sediment transport in the swash of a dissipative beach", Mar. Geol., 216(3), 169-189.

Miles, J., Butt, T. and Russell, P. (2006), "Swash zone sediment dynamics: A comparison of a dissipative and an intermediate beach", Mar. Geol., 231(1-4), 181-200.

Mo, W., Jensen, A. and Liu, P.L.F. (2013), "Plunging solitary wave and its interaction with a slender cylinder on a sloping beach", Ocean Eng., 74, 48-60.

Newberger, P.A. and Allen, J.S. (2007a), "Forcing a three-dimensional, hydrostatic, primitive-equation model for application in the surf zone: 1. Formulation", J. Geophys. Res., 112(8), C08018, doi:10.1029/2006JC003472.

Newberger, P.A. and Allen, J.S. (2007b), "Forcing a three-dimensional, hydrostatic, primitive-equation model for application in the surf zone: 2. Application to DUCK94", J. Geophys. Res., 112(8), C08019, doi:10.1029/2006JC003474.

Nielsen, P. (1992), “Coastal bottom boundary layers and sediment transport”, Adv. Ser. Ocean Eng., 4, World Sci., Singapore.

Ozkan-Haller, H.T. and Li, Y. (2003), "Effects of wave-current interaction on shear instabilities of longshore currents", J. Geophys. Res., 108, 3139, doi:10.1029/2001JC001287.

Razmi, A.M., Bakhtyar, R. and Barry, D.A. (2011), "Numerical simulation of two-phase flow for nearshore hydrodynamics under wave-current interactions", J. Coastal. Res., 64, 1165-1169. 
Reichmüth, B. and Anthony, E.J. (2002), “The variability of ridge and runnel beach morphology: Examples from Northern France”, J. Coastal. Res., 36, 612-621.

Reniers, A.J.H.M., Roelvink, J.A. and Thornton, E.B. (2004), "Morphodynamic modeling of an embayed beach under wave group forcing”, J. Geophys. Res., 109, C01030, doi:10.1029/2002JC001586.

Robinson, C., Brovelli, A., Barry, D.A. and Li, L. (2009), "Tidal influence on BTEX biodegradation in sandy coastal aquifers", Adv. Water Resour., 32(1), 16-28.

Robinson, C.E., Li, L. and Barry, D.A. (2007), "Effect of tidal forcing on a subterranean estuary", $A d v$. Water Resour., 30(4), 851-865.

Rodi, W. (1980), Turbulence models and their application in hydraulics, a state of the art review, IAHR publication, Delft, The Netherlands.

Roelvink, J.A. and Walstra, D.J.R. (2004), " it simple by using complex models". Proceedings of the $6^{\text {th }}$ International Conference on Hydro-Science and Engineering, Advances in Hydro-Science and Engineering, Brisbane, Australia.

Roelvink, D., Reniers, A., Van Dongeren, A., Van Thiel de Vries, J., McCall, R. and Lescinski, R. (2009), "Modelling storm impacts on beaches, dunes and barrier islands", Coast. Eng., 56(11-12), 1133-1152.

Roelvink, J.A. and Reniers, A.J.H.M. (2012), "A guide to modelling coastal morphology", Adv. Coast. Ocean Eng., 12, World Scientific Publications, Singapore.

Ruessink, B.G. (1999), Coast3d main experiment: data summary of offshore wave and waterlevel conditions, subtidal morphology and UU maxi tripods. IMAU Report R99-09, Utrecht University.

Ruessink, B.G., Van Enckevort, I.M.J, Kingston, K.S. and Davidson, M.A. (2000), "Analysis of observed two- and three-dimensional nearshore bar behavior", Mar. Geol., 169(1-2), 161-183.

Shen, Y.M., Ng, C.O. and Zheng, Y.H. (2004), "Simulation of wave propagation over a submerged bar using the VOF method with a two-equation k-epsilon turbulence modeling", Ocean Eng., 31(1), 87-95.

Soulsby, R.L. (2001), "Sediment transport and morphodynamics on complex coastlines - the COAST3D project", Coastal Dynamics '01, Proceedings of the 4th Conference on Coastal Dynamics, Lund Sweden, ASCE.

Thornton, E.B., MacMahan, J. and Sallenger Jr., A.H. (2007), "Rip currents, mega-cusps, and eroding dunes", Mar. Geol., 240(1-4), 151-167.

Tran, T.T., van de Kreeke, J., Stive, M.J.F. and Walstra, D.J.R. (2012), "Cross-sectional stability of tidal inlets: A comparison between numerical and empirical approaches", Coast. Eng., 60, 21-29.

van Leeuwen, S.M., van der Vegt, M. and de Swart, H.E. (2003), "Morphodynamics of ebb-tidal deltas: A model approach", Estuar. Coast. Shelf Sci., 57, 899-907.

van der Wegen, M. and Roelvink, J.A. (2008), "Long-term morphodynamic evolution of a tidal embayment using a two-dimensional, process-based model", J. Geophys. Res., 113, C03016, doi:10.1029/2006JC003983.

van Duin, M.J.P. and Wiersma, N.R. (2002), Evaluation of the Egmond shoreface nourishment. Part 1: Data analysis, WL/Delft Hydraulics Report Z3054/Z3148, http://www.hydraulicengineering.tudelft.nl, last accessed 1 October 2015.

van Rijn, L.C. (1997), "Sediment transport and budget of the central coastal zone of Holland", Coast. Eng., 32(1), 61-90.

van Rijn, L.C. (2011), Principles of sediment transport in rivers, estuaries and coastal seas, AQUA Publications, Amsterdam, The Netherlands.

van Rijn, L.C., Tonnon, P.K. and Walstra, D.J.R. (2011), "Numerical modelling of erosion and accretion of plane sloping beaches at different scales", Coast. Eng., 58(7), 637-655.

Xin, P., Robinson, C., Li, L., Barry, D.A. and Bakhtyar, R. (2010), "Effects of wave forcing on a subterranean estuary", Water Resour. Res., 46, W12505, doi:10.1029/2010WR009632.

Zhao, Q., Svendsen, I.A. and Haas, K. (2003), "Three-dimensional effects in shear waves", J. Geophys. Res., 108, 3270, doi:10.1029/2002JC001306. 


\section{Abbreviations}

$\begin{array}{ll}\text { ADI } & \text { Alternating Direction Implicit } \\ \text { ATM } & \text { Algebraic Turbulence Model } \\ \text { H-LES } & \text { Horizontal Large Eddy Simulation } \\ \text { LST } & \text { Longshore Sediment Transport } \\ \text { NS } & \text { Navier-Stokes } \\ \text { TKE } & \text { Turbulent Kinetic Energy } \\ \text { SWL } & \text { Still Water Level } \\ \text { TDR } & \text { Turbulence Dissipation Rate }\end{array}$

\section{Nomenclature}

\begin{tabular}{|c|c|c|}
\hline Variable & Description & Dimensions \\
\hline$A$ & tidal amplitude & $\mathrm{L}$ \\
\hline$c$ & sediment concentration & $\mathrm{ML}^{-3}$ \\
\hline$d$ & depth below reference (datum) & $\mathrm{L}$ \\
\hline$D$ & sediment diameter & $\mathrm{L}$ \\
\hline $\overrightarrow{\mathrm{g}}$ & gravitational acceleration & $\mathrm{LT}^{-2}$ \\
\hline$h$ & total water depth & $\mathrm{L}$ \\
\hline$H$ & wave height & $\mathrm{L}$ \\
\hline$H_{s}$ & significant wave height & $\mathrm{L}$ \\
\hline$k$ & turbulent kinetic energy & $\mathrm{L}^{2} \mathrm{~T}^{-2}$ \\
\hline$t$ & time & $\mathrm{T}$ \\
\hline$T$ & wave period & $\mathrm{T}$ \\
\hline$U, V$ & $\begin{array}{l}\text { depth-averaged velocity in the horizontal, } \\
\text { and curvilinear co-ordinates, respectively }\end{array}$ & $\mathrm{LT}^{-1}$ \\
\hline$w_{s}$ & sediment settling velocity & $\mathrm{LT}^{-1}$ \\
\hline \multicolumn{3}{|l|}{ Greek } \\
\hline$\omega$ & velocity in the vertical direction & $\mathrm{LT}^{-1}$ \\
\hline$\beta$ & local beach slope & - \\
\hline$\mu$ & dynamic viscosity & $M L^{-1} \mathrm{~T}^{-1}$ \\
\hline$v$ & kinematic viscosity & $\mathrm{L}^{2} \mathrm{~T}^{-1}$ \\
\hline$v_{t}$ & eddy viscosity & $\mathrm{L}^{2} \mathrm{~T}^{-1}$ \\
\hline$\varepsilon$ & turbulence dissipation rate & $\mathrm{L}^{2} \mathrm{~T}^{-3}$ \\
\hline$\varepsilon_{d}$ & sediment eddy diffusivity & $\mathrm{L}^{2} \mathrm{~T}^{-1}$ \\
\hline$\rho_{f}, \rho_{s}$ & fluid and sediment densities, respectively & $\mathrm{ML}^{-3}$ \\
\hline$\zeta$ & water level above reference (datum) & $\mathrm{L}$ \\
\hline$\omega_{j}$ & frequency of tidal components & $\mathrm{T}^{-1}$ \\
\hline$\psi$ & surf scaling parameter & - \\
\hline
\end{tabular}

